\title{
Disruption of a Structurally Important Extracellular Element in the Glycine Receptor Leads to Decreased Synaptic Integration and Signaling Resulting in Severe Startle Disease
}

\author{
Natascha Schaefer, ${ }^{1 *}$ Alexandra Berger, ${ }^{2 *}$ Johannes van Brederode, ${ }^{3}$ Fang Zheng, ${ }^{3}$ Y Yan Zhang, ${ }^{5}$ CSophie Leacock, ${ }^{6}$ \\ Laura Littau, ${ }^{1}$ Sibylle Jablonka, ${ }^{1}$ Sony Malhotra, ${ }^{7}$ Maya Topf, ${ }^{8}$ Friederike Winter, ${ }^{4}$ Daria Davydova, ${ }^{1}$ \\ ㄱoseph W. Lynch, ${ }^{5}{ }^{\circledR}$ Christopher J. Paige, ${ }^{2}$ Christian Alzheimer, ${ }^{3}{ }^{\circledR}$ Robert J. Harvey, ${ }^{6}$ and ${ }^{\circ}$ Carmen Villmann ${ }^{1}$ \\ ${ }^{1}$ Institute of Clinical Neurobiology, Julius-Maximilians-University of Würzburg, 97078 Würzburg, Germany, ${ }^{2}$ Princess Margaret Cancer Centre, University \\ Health Network, University of Toronto, Toronto, Ontario M5G 2M9, Canada, ${ }^{3}$ Institute of Physiology and Pathophysiology, and ${ }^{4}$ Institute of Biochemistry, \\ Friedrich-Alexander-University Erlangen-Nürnberg, 91054 Erlangen-Nürnberg, Germany, ${ }^{5}$ Queensland Brain Institute, University of Queensland, Brisbane \\ 4072, Australia, ${ }^{6}$ Department of Pharmacology, UCL School of Pharmacy, London WC1N 1AX, United Kingdom, ${ }^{7}$ Department of Biochemistry, University \\ of Cambridge, Cambridge CB2 1QW, United Kingdom, and ${ }^{8}$ Institute of Structural and Molecular Biology, UCL Birkbeck College, London WC1E 7HX, \\ United Kingdom
}

Functional impairments or trafficking defects of inhibitory glycine receptors (GlyRs) have been linked to human hyperekplexia/startle disease and autism spectrum disorders. We found that a lack of synaptic integration of GlyRs, together with disrupted receptor function, is responsible for a lethal startle phenotype in a novel spontaneous mouse mutant shaky, caused by a missense mutation, Q177K, located in the extracellular $\beta 8-\beta 9$ loop of the GlyR $\alpha 1$ subunit. Recently, structural data provided evidence that the flexibility of the $\beta 8$ - $\beta 9$ loop is crucial for conformational transitions during opening and closing of the ion channel and represents a novel allosteric binding site in Cys-loop receptors. We identified the underlying neuropathological mechanisms in male and female shaky mice through a combination of protein biochemistry, immunocytochemistry, and both in vivo and in vitro electrophysiology. Increased expression of the mutant GlyR $\alpha 1^{\mathrm{Q} 177 \mathrm{~K}}$ subunit in vivo was not sufficient to compensate for a decrease in synaptic integration of $\alpha 1^{\mathrm{Q} 177 \mathrm{~K}} \beta$ GlyRs. The remaining synaptic heteromeric $\alpha 1{ }^{\mathrm{Q} 177 \mathrm{~K}} \beta \mathrm{GlyRs}$ had decreased current amplitudes with significantly faster decay times. This functional disruption reveals an important role for the GlyR $\alpha 1$ subunit $\beta 8-\beta 9$ loop in initiating rearrangements within the extracellular-transmembrane GlyR interface and that this structural element is vital for inhibitory GlyR function, signaling, and synaptic clustering.

Key words: $\beta 8$ - $\beta 9$ loop; fast decay; glycine receptor; hydrogen bond network; shaky; startle disease

Significance Statement

GlyR dysfunction underlies neuromotor deficits in startle disease and autism spectrum disorders. We describe an extracellular GlyR $\alpha 1$ subunit mutation $(\mathrm{Q} 177 \mathrm{~K})$ in a novel mouse startle disease mutant shaky. Structural data suggest that during signal transduction, large transitions of the $\beta 8-\beta 9$ loop occur in response to neurotransmitter binding. Disruption of the $\beta 8-\beta 9$ loop by the $\mathrm{Q} 177 \mathrm{~K}$ mutation results in a disruption of hydrogen bonds between $\mathrm{Q} 177$ and the ligand-binding residue R65. Functionally, the Q177K change resulted in decreased current amplitudes, altered desensitization decay time constants, and reduced GlyR clustering and synaptic strength. The GlyR $\beta 8-\beta 9$ loop is therefore an essential regulator of conformational rearrangements during ion channel opening and closing.

\section{Introduction}

Glycine receptors (GlyRs) are members of the superfamily of Cys-loop receptors (CLRs), whose structures have recently been resolved by x-ray crystallography or cryo-electron microscopy (EM; Du et al., 2015; Huang et al., 2015). Adult inhibitory GlyRs form pentameric ion channels with a $2 \alpha: 3 \beta$ stoichiometry 
(Grudzinska et al., 2005). Disturbances in glycinergic inhibition are associated with rare disorders such as startle disease (OMIM 149400, hyperekplexia, stiff baby syndrome) and autism spectrum disorders (Harvey et al., 2008; Bode and Lynch, 2014; Pilorge et al., 2016). The genetic causes for startle disease have been defined, with the most common gene GLRA1 (encoding the GlyR $\alpha 1$ subunit) followed by SLC6A5 (glycine transporter 2) and GLRB (GlyR $\beta$ subunit; Harvey et al., 2008; Chung et al., 2010; James et al., 2013). Affected patients show exaggerated startle responses following unexpected acoustic or tactile stimuli, stiffness in infancy, tremor, and loss of postural control during startle episodes (Schaefer et al., 2013). GlyRs are important in the spinal cord for feedback control mechanisms in the nerve-muscle circuit to balance motoneuron firing and in the brainstem for the generation of the respiratory rhythm (Bongianni et al., 2010; Schaefer et al., 2012). The current view of startle disease pathology differentiates between functional impairments and biogenesis defects (Bode and Lynch, 2014). A recent study (Schaefer et al., 2015) demonstrated that startle disease mutations also affect GlyR folding and ER processing, suggesting a higher molecular complexity of disease mechanisms than was previously assumed.

Due to a similar startle phenotype in mice carrying Glral (spasmodic, oscillator) or Glrb (spastic) mutations, mouse models serve as excellent tools to study the underlying pathological mechanisms. Oscillator is a functional GlyR $\alpha 1$ subunit null mutation, while spasmodic harbors an A52S missense mutation in the GlyR $\alpha 1$ subunit ( $\beta 1-\beta 2$ loop), leading to decreased ligand affinities but normal life span (Schaefer et al., 2012). The novel spontaneous mouse mutant shaky carries a missense mutation in exon 6 of Glra1, resulting in a Q177K substitution in the $\beta 8-\beta 9$ loop of the GlyR $\alpha 1$ subunit extracellular domain (ECD). In contrast to spasmodic, homozygous shaky mice suffer from serious neuromotor deficits progressively increasing from postnatal day 14 (P14) until death, indicating that disruption of the $\beta 8-\beta 9$ loop substantially impairs glycinergic function and is incompatible with life.

To date, the $\beta 8-\beta 9$ loop has mainly been investigated by in vitro mutagenesis studies in other CLRs (Thompson et al., 2006; Hibbs et al., 2009). These studies revealed effects on ligand efficacies or affinities, arguing for an involvement of the $\beta 8-\beta 9$ loop in the ligand-binding process. This view was recently expanded by the identification of the $\beta 8-\beta 9$ loop forming an allosteric binding site for the antipsychotic compound chlorpromazine in the closely related Erwinia ligand-gated ion channel ELIC (Nys et al., 2016). Structural data have demonstrated that the $\beta 8-\beta 9$ loop is part of the signal transduction unit, transferring the closed state upon ligandbinding into the open configuration and back to the closed ion chan-

Grant MR/M019292/1 to M.T.). N.S. was supported by the GSLS Würzburg. We thank Professors K. Schiebel and M. Sendtner for critical reading of the manuscript and helpful comments. We also thank Professor C.-M. Becker for providing mutant mouse lines. In addition, we thank Nadine Vornberger and Gudrun Schell for excellent technical assistance.

*N.S and A.B. contributed equally to this work

The authors declare no competing financial interests.

Correspondence should be addressed to Dr. Carmen Villmann, Institute of Clinical Neurobiology, University of Wuerzburg, Versbacherstrasse 5, D-97078 Würzburg, Germany. E-mail: villmann_c@ukw.de.

F. Winter's present address: Department of Physiology, Anatomy and Genetics, University of Oxford, Oxford, UK.

R.J. Harvey's present address: School of Health and Sport Sciences, University of the Sunshine Coast, Queensland, Australia.

DOI:10.1523/JNEUROSCI.0009-17.2017

Copyright $\odot 2017$ Schaefer, Berger et al.

This is an open-access article distributed under the terms of the Creative Commons Attribution License Creative Commons Attribution 4.0 International, which permits unrestricted use, distribution and reproduction in any medium provided that the original work is properly attributed. nel state (Du et al., 2015; Morales-Perez et al., 2016). However, the role of the $\beta 8-\beta 9$ loop in disease mechanisms is unclear.

Here, we found that the $\beta 8-\beta 9$ loop is involved in GlyR synaptic clustering as well as neurotransmitter sensitivity and that a defect in these mechanisms causes severe startle disease. In neuronal cultures and spinal cord tissue from shaky mice, we observed an increased expression level of GlyR $\alpha 1^{\text {Q177K }}$, which was an unsuccessful attempt at compensation for an observed lack of GlyR integration into synapses. Decreased agonist efficacy and faster decay times of $\alpha 1^{\mathrm{Q} 177 \mathrm{~K}} \beta$ GlyRs were recorded in artificial synapses and ex vivo brainstem slices. Recordings after the onset of neuromotor symptoms revealed significant reductions in current amplitudes, frequencies, and decay times but no changes in rise times in shaky homozygotes. Thus, shaky represents the first in vivo model highlighting that $\beta 8-\beta 9$ loop is a key regulator of GlyR signaling as it is essential for conformational rearrangements governing both receptor clustering and ion channel gating.

\section{Materials and Methods}

Mouse lines. The novel mutant mouse strain shaky arose as a spontaneous mutation in the animal colony of C. Paige (University Health Network Research, Toronto, ON, Canada) in a mixed 129X1/SvJ/C57BL/6 strain. Mice were transferred into the animal facility of the Institute of Clinical Neurobiology (Würzburg, Germany), where mice were housed under pathogen-free conditions; water and food were available ad libitum. All mice were the offspring of heterozygous $+/ s h$ matings or crosses with $129 \mathrm{X} 1 / \mathrm{SvJ}$ wild-type mice. Experiments were approved by the local veterinary authority (Veterinäramt der Stadt Würzburg) and the Ethics Committee of Animal Experiments (i.e., Regierung von Unterfranken, Würzburg, Germany; license \#55.2-2531.01-09/14). Oscillator and spasmodic mice were a gift from C.-M. Becker (Institute of Biochemistry, Friedrich-Alexander University Erlangen-Nürnberg, Erlangen-Nürnberg, Germany) and derived via embryo transfer into our animal facility. For all experiments, animals of both sexes were used.

Experimental design and statistical analysis. For each experiment, the genotype and the sample size are described in the legend of the corresponding figure. Animals of both sexes were used since no significant differences were detected on the basis of sex, so data were therefore pooled. Replicates were performed with tissue from different animals or transfection material from independent transfection rounds, and $n$ values are always provided in figure legends. Recordings of transfected cells have been made from at least three independent experiments (except $\mathrm{EC}_{50}$ values were recorded from one set of experiments). The number of cells recorded are documented in figure legends. Recordings from slices were made from at least three independent animals, and the numbers of cells recorded from how many animals differed are shown in figure legends. All other experiments have been exhibited at least three times. Statistical significance was calculated using the one-way ANOVA and the unpaired $t$ test. The analyses were performed using Origin 6.0 (Microcal Software), ImageJ version 1.50e software (https://imagej.nih.gov/ij/), and Graphics Prism Program version 5.0 (GraphPad Software). All $p$ values are given in the Results section.

Behavioral analysis. The neuromotor phenotype of homozygous Glral ${ }^{\text {sh/sh }}$ mice was investigated by overall visual examination, hindfeet clasping, righting ability, assessment of gait by footprint recordings, body weight, and survival. Videos were recorded with the multi-conditioning system (256060 series) from TSE. Pictures were taken on P14 and P21, and body weight was checked over a period of 6 weeks every 2-3 d.

Rotarod. Mice were tested on a motorized rotarod (grooved rod $\varnothing$ $4 \mathrm{~cm}$; 11-cm-wide compartments; acceleration speed, 2-20 rpm). The duration of time that mice remained on the rod during rotation was measured with a maximum of $300 \mathrm{~s}$ per animal. Diazepam was injected intraperitoneally at a concentration of $0.5 \mathrm{mg} / \mathrm{kg}$ in a total volume of $100 \mu \mathrm{l}$ of sterile PBS. Control animals were injected with PBS.

RNA isolation and reverse transcription-PCR. RNA extraction from tissue was performed as recommended by the manufacturer (PEQLAB) using peqGOLD RNAPure. One microgram of RNA was used for reverse 
transcription (RT)-PCR. We used RevertAid M-MuLV (Moloney murine leukemia virus) $\mathrm{RT}(200 \mathrm{U} / \mu \mathrm{l})$ provided with $5 \times$ reaction buffer and deoxy (d) ATP, dCTP, dGTP, dTTP (10 mm each), and random hexamers (50-200 ng; Thermo Fisher Scientific). Two microliters of cDNA were used for amplification of the housekeeping gene $\beta$-actin; GlyR $\alpha 1$, $\alpha 2$, and $\beta$; gephyrin, and $\mathrm{GlyT} 1\left(95^{\circ} \mathrm{C}\right.$ for $5 \mathrm{~min} ; 25$ cycles at $95^{\circ} \mathrm{C}$ for $30 \mathrm{~s}$, $55^{\circ} \mathrm{C}$ for $30 \mathrm{~s}, 72^{\circ} \mathrm{C}$ for $30 \mathrm{~s}$, and $72^{\circ} \mathrm{C}$ for $10 \mathrm{~min}$ ).

Cell lines and primary neurons. Human embryonic kidney 293 (HEK293) cells were grown in minimum essential medium (Thermo Fisher Scientific), supplemented with $10 \%$ fetal calf serum, L-glutamine (200 mM), and $50 \mathrm{U} / \mathrm{ml}$ penicillin and streptomycin at $37^{\circ} \mathrm{C}$ and $5 \% \mathrm{CO}_{2}$. Cells were transiently transfected using a modified calcium phosphate precipitation method. All experiments concerning protein biochemistry with HEK293 cells were performed $48 \mathrm{~h}$ after transfection. Primary spinal cord neuronal cultures were prepared at embryonic day 13 (E13). A piece of tail tissue of each embryo was used for genotyping. Briefly, every spinal cord was trypsinized using $1 \mathrm{ml}$ of trypsin/EDTA $(1 \mathrm{mg} / \mathrm{ml})$ and $10 \mu \mathrm{l}$ of DNase I (final concentration, $0.1 \mathrm{mg} / \mathrm{ml}$ ), incubating the suspension at $37^{\circ} \mathrm{C}$ for $30 \mathrm{~min}$. Trypsinization was stopped with $100 \mu \mathrm{l}$ of fetal calf serum (final concentration, 10\%). After a three-step trituration, the cells were centrifuged at $300 \mathrm{rpm}$ for $15 \mathrm{~min}$. Trituration was repeated. Cells were plated on a $3 \mathrm{~cm}$ dish with four poly-lysine-covered coverslips and incubated at $37^{\circ} \mathrm{C}$ with $5 \% \mathrm{CO}_{2}$ at $95 \%$ humidity. Spinal cord neurons were grown in neurobasal medium plus $5 \mathrm{ml}$ of L-glutamine (200 mM) plus B27 supplement (Thermo Fisher Scientific) with an exchange of $50 \%$ medium after $6 \mathrm{~d}$ in culture. Neurons older than day in vitro 21 were used for experiments.

Membrane preparations and biotinylation of cell surface proteins. For membrane protein analysis, crude cell membranes were prepared from transfected cells or mouse tissue (Sontheimer et al., 1989). Biotinylation experiments were performed as described previously (Atak et al., 2015).

Radioligand-binding assays. $\left[{ }^{3} \mathrm{H}\right]$ strychnine displacement assays were performed using filtration assays with triplicates of $80 \mu \mathrm{g}$ of membrane protein. Samples were incubated for 30 min either with $30 \mathrm{~mm}$ glycine or buffer B ( $25 \mathrm{~mm}$ potassium phosphate buffer, $200 \mathrm{~mm} \mathrm{KCl}$ ). Then either glycine or buffer $\mathrm{B}$ was replaced by a range of $\left[{ }^{3} \mathrm{H}\right]$ strychnine concentrations $(1,10,20,50,100$, and $200 \mathrm{~nm}$; specific activity, $30 \mathrm{Ci} / \mathrm{mmol}$; DuPont NEN; Kling et al., 1997). Binding data were analyzed by a nonlinear algorithm provided by the program Origin version 6.0 (Microcal Software).

Western blot and immunostaining. For SDS-PAGE, 11\% polyacrylamide gels were freshly prepared, followed by Western blot on nitrocellulose membranes (GE Healthcare). Membranes were blocked for $1 \mathrm{~h}$ with $5 \%$ BSA in TBS-T (TBS with $1 \%$ Tween 20). Primary antibodies were incubated overnight at $4^{\circ} \mathrm{C}$. GlyR proteins were detected with the pan- $\alpha$ antibody for GlyRs (mAb4a; 1:500; catalog \#146 011, Synaptic Systems), GlyR $\alpha 1$ antibody (mAb2b; 1:1500; catalog \#146 003, Synaptic Systems), gephyrin antibody (1:500; catalog \#147 003, Synaptic Systems), $\beta$-actin (1:5000; catalog \#GTX26276, GeneTex), or pan-cadherin (1: 1500 ; catalog \#4068, Cell Signaling Technology) served as a loading control. Signals were detected using the ECL Plus System (GE Healthcare). Image quantification for Western blots was performed using ImageJ version 1.50e software (https://imagej.nih.gov/ij/). Data were analyzed using Student's $t$ test (ANOVA) or one-way ANOVA, and values below ${ }^{\star} p<0.05$ were considered significant $\left({ }^{\star *} p<0.01,{ }^{* *} p<0.001\right)$. The values are displayed as the mean \pm SEM or as otherwise noted. The graphs were generated using Origin version 6.0 software (Microcal Software).

Immunohistochemistry. Spinal cords were dissected, rapidly frozen on dry ice, and embedded in Tissue-Tek (Sakura Finetek). Transverse slices with a thickness of $8-9 \mu \mathrm{m}$ were cut with a cryostat (Jung Frigocut 2800 E, Leica). Four to six slices were transferred to glass slides $(25 \times 75 \times$ $1.0 \mathrm{~mm}$; SuperFrostR Plus, Menzel Gläser/Thermo Scientific) and stored for further analysis at $-80^{\circ} \mathrm{C}$. For immunostaining, tissue slides were fixed for $30 \mathrm{~s}$ in ice-cold 2\% PFA and immersed once in $50 \mathrm{mM} \mathrm{NH}_{4} \mathrm{Cl}$ following quenching for $30 \mathrm{~min}$ in $0.1 \mathrm{~mm}$ glycine in PBS. Tissue slices were blocked by $10 \%$ normal horse serum in PBS for $1 \mathrm{~h}$ at room temperature. The slides were incubated with antibodies GlyR $\alpha 1$ (1:250; mAb2b; catalog \#146 111, Synaptic Systems), VGAT (1:300; catalog \#131
003, Synaptic Systems), gephyrin (1:200; catalog \#147 003, Synaptic Systems), and synapsin (1:300; catalog \#574778, Calbiochem) in $10 \%$ normal horse serum in PBS overnight at $4^{\circ} \mathrm{C}$. After three washing steps with PBS for $10 \mathrm{~min}$ each, tissue was incubated with secondary antibodies coupled to Cy3 and Alexa Fluor 488 (1:1000, Dianova) diluted in 10\% normal horse serum in PBS for $45 \mathrm{~min}$ at $22^{\circ} \mathrm{C}$. For staining of the cell nuclei, slides were incubated in Molecular Probes DAPI solution (Thermo Fisher Scientific) diluted 1:1500 in PBS for $10 \mathrm{~min}$ at room temperature in a dark chamber. Finally, the slides were mounted with aqua polymount (Polysciences).

Confocal microscopy, and image acquisition and analysis. Images were acquired using an inverted IX81 microscope equipped with an Olympus FV1000 confocal laser scanning system, an FVD10 SPD spectral detector, and diode lasers of $405 \mathrm{~nm}$ (DAPI), $495 \mathrm{~nm}$ (Alexa Fluor 488), and 550 $\mathrm{nm}(\mathrm{Cy} 3)$. All images shown were acquired with an Olympus UPLSAPO $60 \times$ (oil objective; numerical aperture, 1.35 ) objective. The images were further developed and organized by Adobe Photoshop CS5 and Illustrator software or Corel Photopaint, Corel Graphic Suite $\times 6$.

Image analysis for quantification. Single coverslips were acquired using settings of a photomultiplier identically applied to all samples quantified in one experiment. Maximal projection images were created from confocal stacks using NIH ImageJ 1.50e software (https://imagej.nih.gov/ij/). Nonspecific background was removed using threshold subtraction. In all experiments, clusters of GlyRs were defined semiautomatically by setting rectangular regions of interest (ROIs) with dimensions of approximately $8 \times 8$ pixels around local intensity maxima in the channel with GlyR $\alpha 1$-specific (mAb2b) staining using OpenView software (Tsuriel et al., 2006). Mean immunofluorescence (IF) intensities were measured in a $4 \times 4$ pixel box within every ROI in all corresponding channels. Obtained IF intensities were normalized to the mean intensity of control (shaky vs wild type). All results of IF analysis are shown as the mean \pm SEM. All statistical analyses were performed with GraphPad Prism version 5.0 software (GraphPad Software)

Counting of motoneurons. Mice were deeply anesthetized and transcardially perfused as described previously (Jablonka et al., 2000). Slices were stained with cresyl violet, and motoneurons were counted in every 10th section of the lumbar spinal cord (L1-L6). The raw counts were corrected for double counting of split nucleoli as described previously (Masu et al., 1993). Differences between groups were evaluated with Student's $t$ test (unpaired; significance level, ${ }^{\star} p<0.05$ ), applying the Graphics Prism Program version 5.0 (GraphPad Software).

Molecular modeling of the GlyR $\alpha 1$ subunit Q177K mutation. The cryo-EM structure [Electron Microscopy Data Bank (EMDB), ID EMD6345; Protein Data Bank (PDB), ID 3JAE] of the zebrafish GlyR $\alpha 1$ subunit was used to study the structural and functional effects of the Q177K substitution. The position of glycine in the binding site was modeled based on the position of glutamate in the binding site of GluCl (PDB ID, 3RHW) using a superposition of the two receptors with MODELLER (Sali and Blundell, 1993). Flexible fitting was performed using MODELLER/Flex-EM (Topf et al., 2008; Joseph et al., 2016). The nonsynonymous substitution Q177K was modeled into the GlyR using the swapaa command in Chimera (Pettersen et al., 2004) based on the Dunbrack backbone-dependent rotamer library (Dunbrack, 2002) and taking into account the lowest clash score, highest number of $\mathrm{H}$-bonds, and highest rotamer probability. Flexible fitting resulted in moving R65 into the EM density.

Electrophysiological recordings from transfected cells. Maximal current amplitudes $\left(I_{\max }\right)$ were measured by patch-clamp recordings in a wholecell configuration from transfected HEK293 cells. Current signals were amplified with an EPC-9 amplifier (HEKA). Whole-cell recordings were performed by the application of ligand using a U-tube system bathing the suspended cell in a laminar flow of solution, giving a time resolution for equilibration of $10-30 \mathrm{~ms}$. Glycine was used at concentrations between $0.3 \mu \mathrm{M}$ and $3 \mathrm{~mm}$. The external buffer consisted of the following (in $\mathrm{mm}$ ): $137 \mathrm{NaCl}, 5.4 \mathrm{KCl}, 1.8 \mathrm{CaCl}_{2}, 1 \mathrm{MgCl}_{2}$, and 5 HEPES, pH adjusted to 7.4 with $\mathrm{NaOH}$. The internal buffer consisted of the following (in mM): 120 $\mathrm{CsCl}, 20 \mathrm{~N}(\mathrm{Et}){ }_{4} \mathrm{Cl}, 1 \mathrm{CaCl}_{2}, 2 \mathrm{MgCl}_{2}, 11$ EGTA, and $10 \mathrm{HEPES}, \mathrm{pH}$ adjusted to 7.2 with $\mathrm{CsOH}$. Recording pipettes were fabricated from borosilicate capillaries with an open resistance of 4-6 M $\Omega$. Current re- 
sponses were measured at a holding potential of $-60 \mathrm{mV}$. All experiments were performed at $22^{\circ} \mathrm{C}$. For desensitization analysis, whole-cell current traces were transferred to Microcal Origin version 6.0 (Microcal Software), and the decaying current phase was analyzed using a single exponential function plus a constant, as shown in Equation 1:

$$
I_{\mathrm{obs}}=I_{1} * e^{\left(-t / \tau_{1}\right)}+I_{\text {const }},
$$

where $I_{\mathrm{obs}}$ is the observed total current amplitude, $I_{1}$ is the fraction of current desensitizing with time constant $\tau_{1}$, and $I_{\text {const }}$ is the amplitude of the nondesensitizing current fraction. A single exponential decay plus a constant term were sufficient to describe desensitization behavior. Functional constants of the coexpressed subunits were compared using a $t$ test. A probability of error of ${ }^{\star} p<0.05$ was considered significant $\left({ }^{* *} p<0.01\right.$, $\left.{ }^{\star * *} p<0.001\right)$.

Electrophysiological recordings from artificial synapses. Experiments were performed as described by Zhang et al. (2015).

Brainstem slice preparation and whole-cell recordings. Electrophysiological experiments were performed on brainstem slices from 18 - to 24-dold mice. After anesthesia and decapitation, brainstem tissue was rapidly removed and immersed in ice-cold "high-sucrose" artificial CSF (aCSF) containing the following (in $\mathrm{mM}$ ): 75 sucrose, $125 \mathrm{NaCl}, 3 \mathrm{KCl}, 0.3 \mathrm{CaCl}_{2}$, $7 \mathrm{MgCl}_{2}, 1.25 \mathrm{NaH}_{2} \mathrm{PO}_{4}, 25 \mathrm{NaHCO}_{3}$, and 30 D-glucose and bubbled with carbogen $\left(95 \% \mathrm{O}_{2} / 5 \% \mathrm{CO}_{2}\right)$ at $\mathrm{pH} 7.4$. Transverse slices, 250-350 $\mu \mathrm{m}$ thick, containing the PreBötzinger complex (PreBötC) were cut and transferred into warm $\left(35^{\circ} \mathrm{C}\right)$ aCSF for $15 \mathrm{~min}$ and kept at room temperature thereafter in normal aCSF for at least $1 \mathrm{~h}$ before using. Recordings were performed in normal aCSF buffer, $\mathrm{pH} 7.4$, that contained the following (in mM): $125 \mathrm{NaCl}, 3 \mathrm{KCl}, 2 \mathrm{CaCl}_{2}, 2 \mathrm{MgCl}_{2}, 1.25 \mathrm{NaH}_{2} \mathrm{PO}_{4}, 25$ $\mathrm{NaHCO}_{3}$, and $10 \mathrm{D}$-glucose at $30^{\circ} \mathrm{C}$. The brainstem region of interest was identified based on their location relative to nearby landmarks such as the inferior olive, hypoglossal nerve and nucleus ambiguus (for PreBötC). Whole-cell recordings were performed with patch pipettes filled with an internal solution composed of (in $\mathrm{mm}$ ): $130 \mathrm{CsCl}, 3 \mathrm{MgCl}_{2}$, 5 EGTA, 5 HEPES, $2 \mathrm{Na}_{2}$-ATP, $0.3 \mathrm{Na}_{3}$-GTP, and 5 QX-314, pH 7.3. The electrode resistance ranged from 3 to $5 \mathrm{M} \Omega$ when filled with internal solution. Whole-cell currents were recorded at a holding potential of $-70 \mathrm{mV}$ (corrected for liquid junction potential), filtered $(2-6 \mathrm{kHz}$ ), and sampled at $20 \mathrm{kHz}$ using a Multiclamp 700B Amplifier in conjunction with a Digidata 1440A interface and pClamp10 software (Molecular Devices).

Constant current pulses (width, $0.01 \mathrm{~ms}$ ) of 100-400 $\mu \mathrm{A}$ were delivered every $10 \mathrm{~s}$ to a bipolar tungsten electrode located in close vicinity to the preBötC to evoke synaptic responses. Glycinergic IPSCs were pharmacologically isolated by ionotropic glutamate receptor antagonist kynurenic acid (KA; $2 \mathrm{~mm}$ ) and $\mathrm{GABA}_{\mathrm{A}}$ receptor antagonist bicuculline methiodide (BMI; $10 \mu \mathrm{M})$. Glycine $(50 \mu \mathrm{M})$ was used to induce postsynaptic response in the presence of tetrodotoxin (TTX; $1 \mu \mathrm{M}$ ) and kynurenic acid/bicuculline. Strychnine $(10 \mu \mathrm{M})$ was applied in some experiments to verify the glycinergic origin of IPSC or to block glycine-induced currents. The input-output relationship of evoked IPSC was plotted with the negative peaks of synaptic response against the stimulating intensity.

Miniature glycinergic IPSCs (mIPSCs) were pharmacologically isolated by perfusing the slices with aCSF in the presence of KA, BMI, and TTX. Individual events were detected with Clampfit software (Molecular Devices) using a template method with amplitude threshold set to 5-6 * $\sigma_{\text {noise }}$. The peak amplitude, $10-90 \%$ rise time, $90-10 \%$ decay time, and area were measured and averaged over a minimum of 20 events. For mIPSC kinetics, only nonoverlapping events with relatively fast rise times $(<2 \mathrm{~ms})$ and a smooth decay were included in the analysis.

\section{Results}

Impairment of GlyR $\alpha 1$ subunit $\beta 8-\beta 9$ loop underlies a neuromotor phenotype and lethality in the mouse mutant shaky

Our current view on startle disease has focused on GlyR variants that affect either receptor function or biogenesis. However, potential in vivo compensatory mechanisms are still a matter of debate. Here, we used a novel mouse startle disease model, shaky, to demonstrate that the extracellular GlyR $\alpha 1$ subunit $\beta 8-\beta 9$ loop is a key structural element for GlyR function, signaling, and receptor clustering. The combined functional disruption and synaptic clustering defects in this model allowed us to study the compensatory mechanisms of both effects in vivo.

The spontaneous mouse mutant shaky became conspicuous when $\sim 25 \%$ of pups at the age of 2 weeks developed a severe motor defect characterized by typical hindfeet clasping when picked up by their tails (Fig. 1A), including tremor, muscle spasms, a twitchy tail, and stiffness. These neuromotor symptoms are similar to oscillator mice (Buckwalter et al., 1994), a mouse model of startle disease with a progressive severe phenotype due to truncated nonfunctional GlyR $\alpha 1$ subunit (Fig. 1A). During episodes of tremor, shaky mice display a hunched, stiff posture (Fig. $1 A$, bottom). The righting ability is poor with a ninefold increase in righting time between weeks 3 and 4 of life $\left[\mathrm{Glral}^{+/+}\right.$, $0.1 \pm 0.1 \mathrm{~s} ;$ Glral $^{\text {sh } / \mathrm{sh}}, 32 \pm 10 \mathrm{~s}\left({ }^{*} p=0.0351\right.$ at $\left.\mathrm{P} 14-\mathrm{P} 21\right)$; Glra1 $^{+/+}, 0.1 \pm 0.1 \mathrm{~s} ;$ Glral $^{\text {sh/sh }} 273 \pm 68 \mathrm{~s}\left({ }^{* *} \mathrm{p}=0.00079\right.$ at P22-P28, $t$ test); Fig. $1 B]$. Homozygous mutant mice are usually smaller than their littermates and die at 3-6 weeks of age (Fig. 1C). Sequencing of Glral in shaky mice $\left(\mathrm{Glra}^{\mathrm{sh} / \mathrm{sh}}\right)$ and littermate controls revealed two sequence variants: c.T198C in exon 3 (synonymous, p.N38N) and c.C613A in exon 6 (missense, p.Q177K; numbers refer to mature proteins). The identification of a GlyR missense mutation provided a plausible explanation for the observed severe motor phenotype similar to other startle disease mouse models. The synonymous change in exon 3 was not causative and is a common variant that comes from the hybrid C57BL/6129SvJ background (rs26948271) of shaky. However, breeding of heterozygotes for the missense mutation Q177K resulted in an autosomal-recessive inheritance of the mutation following backcrosses from the original mixed background of C57BL/6129SvJ over $>10$ generations (614 wild-type animals, 303 heterozygous animals, 138 shaky animals). Sequencing of other candidate genes affected in startle disease excluded further pathogenic sequence variations, as only common single nucleotide variants were found (Glrb: exon 5, c.A555G, p.L163L, rs13477223; SLC6A5: exon 2, c.A109G, p.T37A, rs31048165).

To confirm that shaky results from defects in glycinergic transmission, heterozygous shaky mice were bred with heterozygous spasmodic or oscillator mice. Spasmodic carries a different missense mutation A52S in the GlyR $\alpha 1$ subunit that affects glycine efficacy but results in a mild phenotype with tremor episodes but normal life span for the animals (Buckwalter et al., 1994; Saul et al., 1994). Eight matings of shaky and oscillator heterozygotes generated 10 mice with severe motor deficits with onset of symptoms at P14 and a life span of 4 weeks (Fig. 1D). Genotyping of the pups exhibited heterozygosity of affected mice for the oscillator and shaky mutations (Glra $1^{\text {sh/ot }}$ ), confirming the validity of this test for allelism. By contrast, heterozygous Glral $^{\text {spd/sh }}$ mice survive like homozygous $\mathrm{Glra1}^{\text {spd/spd }}$ mice with similar mild neuromotor deficits upon tactile or acoustic stimuli (Fig. 1D). Together, these data provided strong evidence that the pathophysiological mechanism in the spontaneous mouse model shaky is a missense mutation (Q177K) in Glra1.

\section{Motor deficits in homozygous shaky mice are improved by benzodiazepine treatment}

Due to their impaired motor control, shaky mice performed very poorly on the rotarod test $\left(\right.$ Glra1 $^{+/+}$time on rod, $288 \pm 5 \mathrm{~s}$; Glra1 ${ }^{\text {sh } / s h}$ time on rod, $15 \pm 3 \mathrm{~s} ;{ }^{* * *} p=6.935 \mathrm{E}-27, t$ test; Fig. $\left.1 E\right)$. Humans suffering from startle disease respond to treatment with benzodiazepines such as clonazepam, which improves symptoms 
A

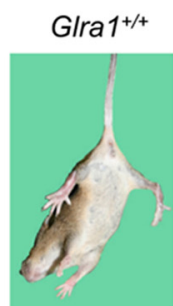

Glra1sh/sh
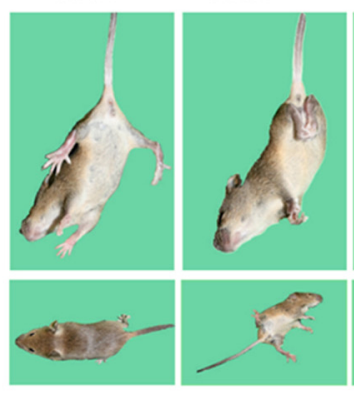

Glra1otot
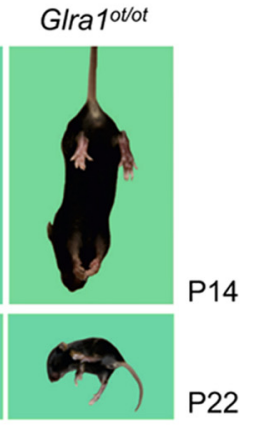

B

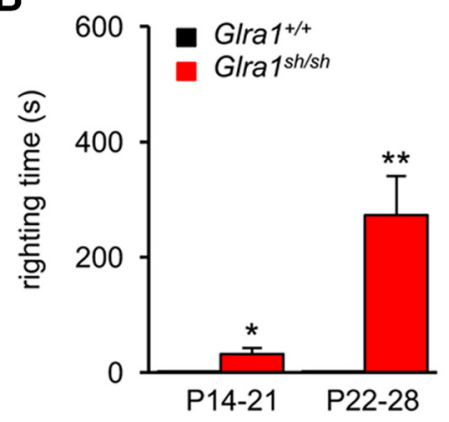

C

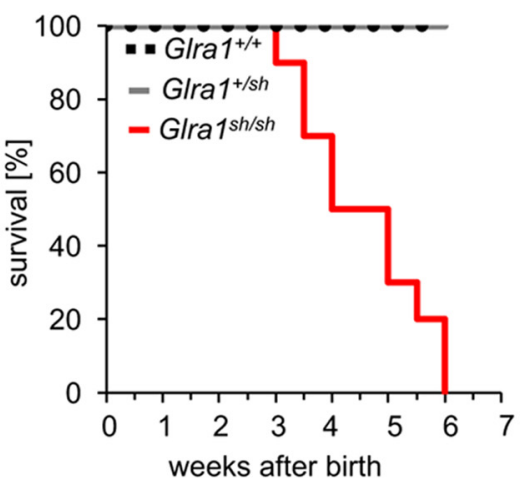

D

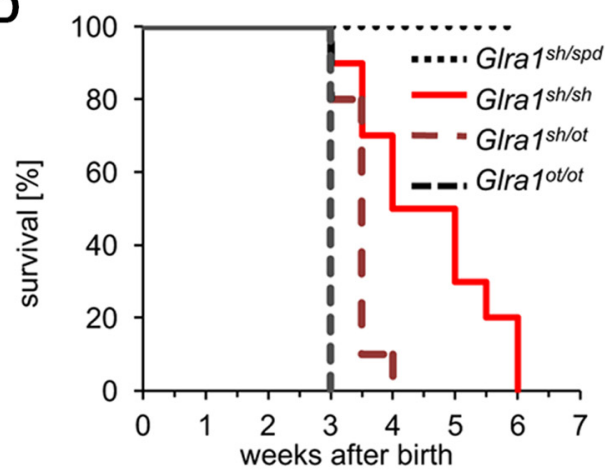

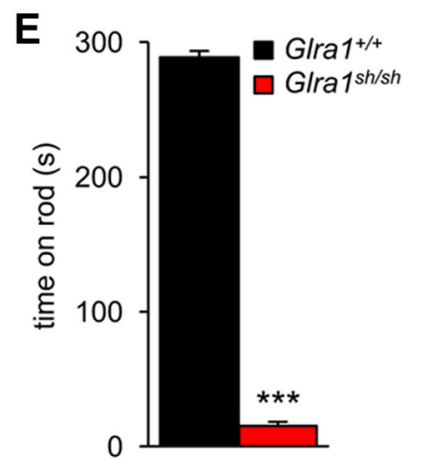

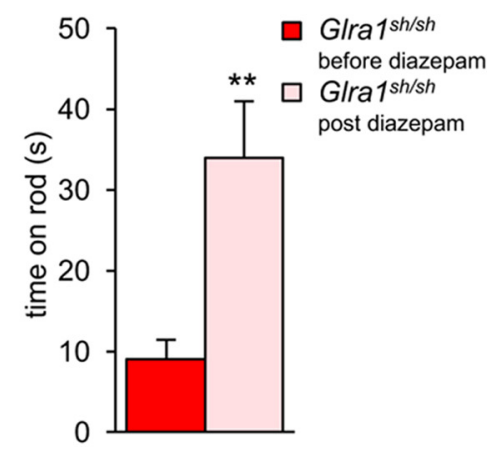

Figure 1. Shaky mice display a neuromotor phenotype and carry a Glra 1 mutation. A, Comparison of hindfeet and hindlimb clenching behavior of wild-type GIra ${ }^{+/+}$, Glra ${ }^{\text {sh/sh }}$, and Glra $1^{\text {ot/ot }}$ mice at P14 when mice were lifted by the tails, and progressive motor phenotype at P22 (bottom panels) with rigidity in forelimbs, hindlimbs, and tails. $B$, Impaired righting time of mutant $G$ Ira ${ }^{\text {sh/sh }}$ mice. Time GIra ${ }^{\text {sh/sh }}$ mice are required to get up at P14 to P21 compared with wild type, prolonged righting time at stage P22 to P28. Cutoff time was 10 min, and 2 of 10 mice older than $21 \mathrm{~d}$ timed

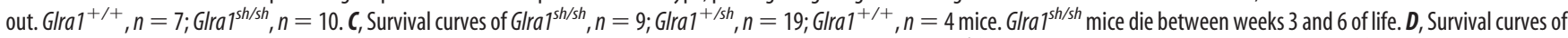
backcross experiments with GlyR mutant mouse lines spasmodic (spd) and oscillator (ot): note that heterozygous Glra ${ }^{\text {sh/ot }}$ mice die 4 weeks after birth similar to Glra ${ }^{\text {ot/ot }}$ mice and in contrast to

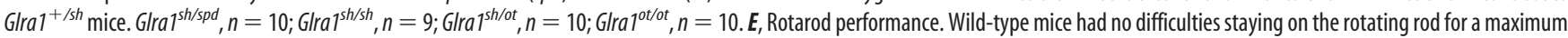
time of $300 \mathrm{~s}$. Glra ${ }^{\text {sh/sh }}$ mice were able to remain on the rod for only a few seconds. Glra ${ }^{+/+}, n=17 ; G \operatorname{lra} 1^{\text {sh/sh }}, n=12 .{ }^{*} p<0.05 ;{ }^{* *} p<0.01 ;{ }^{* * *} p<0.001$.

by potentiating GABAergic transmission. Therefore, shaky mice were tested on the rotarod prior to (baseline) and after intraperitoneal injection of $0.5 \mathrm{mg} / \mathrm{kg}$ diazepam. After this treatment, shaky mice showed a significant improvement in their performance (after diazepam: $t=34 \pm 7 \mathrm{~s} ; n=10 ;{ }^{*} p=0.00102$, $t$ test) on the rod (Fig. 1E). Again, improvement of the symptoms following diazepam treatment provides further evidence for a glycinergic transmission defect in shaky mice.

\section{Shaky GlyRs have disrupted ligand binding, but the} neuromotor phenotype does not result from disturbed receptor biogenesis

A first analysis of key proteins at the glycinergic synapse (GlyR $\alpha 2$, GlyR $\beta$, gephyrin, GlyT1) in wild-type $(+/+)$, heterozygous $(+/ s h)$, and homozygous shaky $(s h / s h)$ mice revealed no obvious differences at the mRNA level (Fig. 2A). At the protein level (Fig.
$2 B-E)$, the distinct expression of GlyR $\alpha$ subunits was detected in brainstem and spinal cord, but there was only faint expression in cortex (presumably, $\alpha 2$ or $\alpha 3$ subunits). Furthermore, specific $\alpha 1$ expression was enhanced in spinal cord of Glra1 ${ }^{\text {sh/sh }}(p=0.09$, nonsignificant, $t$ test) and significantly increased in brainstem ${ }^{*} p=0.019, t$ test $)$ at $\mathrm{P} 21$ when shaky mice exhibit a severe neuromotor phenotype (Fig. $2 B, C$ ). No GlyR $\alpha 1$ expression was observed in cortex. Gephyrin was also increased concomitantly with GlyR $\alpha 1$ in the brainstem $\left({ }^{\star} p=0.045, t\right.$ test) of affected animals (Glra1 ${ }^{\text {sh/sh}}$; Fig. 2 B,D). The broad expression of gephyrin in the cortex is consistent with a major role in $\mathrm{GABA}_{\mathrm{A}}$ receptor clustering within this brain area (Tyagarajan and Fritschy, 2014). A developmental analysis of spinal cord, brainstem, and cortex from P0 to P28 indicated that GlyR $\alpha 1$ subunit expression in Glral $^{\text {sh/sh }}$ was indistinguishable from that observed in Glra1 ${ }^{+/+}$ mice and began at P6 (Fig. 3A). Furthermore, the subunit switch 
A

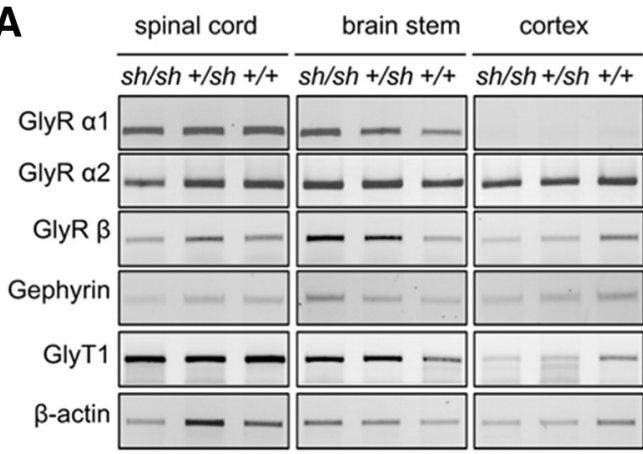

C

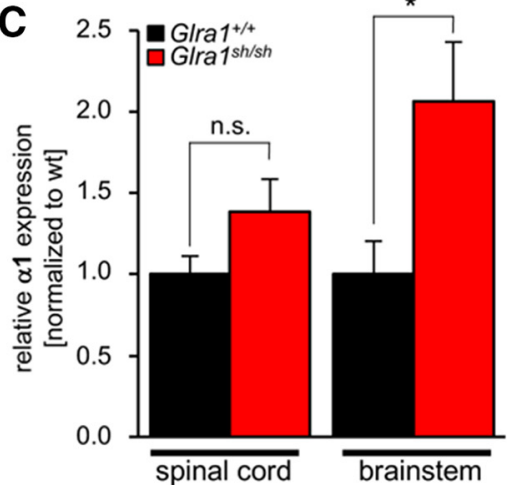

IE

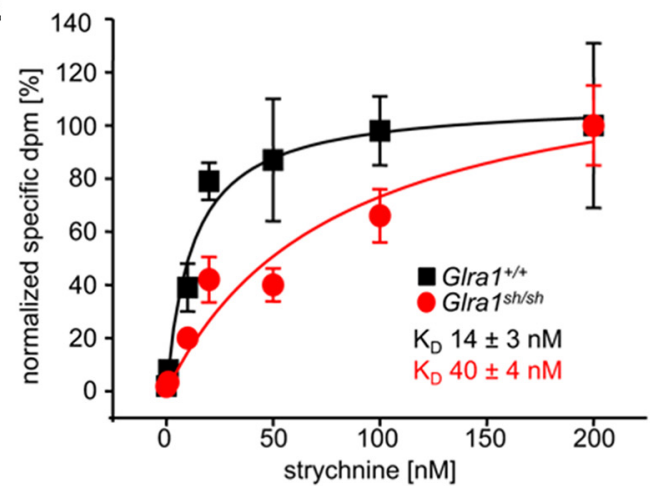

B $\frac{\text { spinal cord }}{\mathrm{kDa} s h / s h+/ s h+/+} \frac{\text { brain stem }}{s h / s h+/ s h \quad+/+} \frac{\text { cortex }}{\text { sh/sh }+/ s h+/+}$

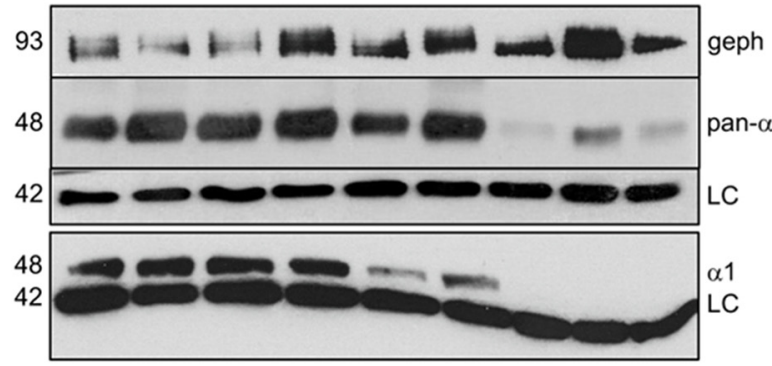

D

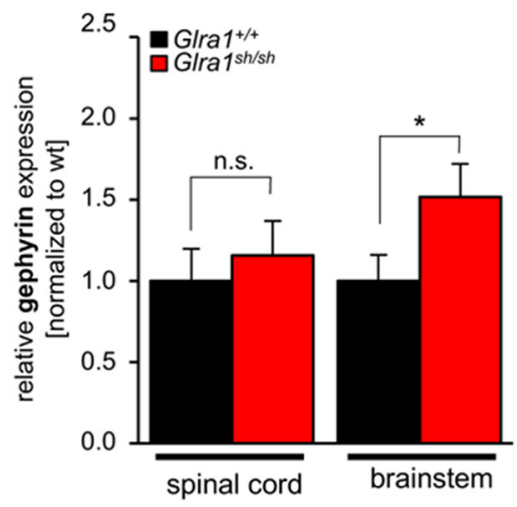

Figure 2. Glra ${ }^{\text {sh/sh }}$ mice display protein expression differences and reduced agonist binding. $\boldsymbol{A}$, Transcript analysis of GlyR $\alpha 1, \alpha 2$, and $\beta$ subunits, the scaffold protein gephyrin, the glycine transporter 1 (GlyT1), and $\beta$-actin (housekeeping gene) in spinal cord, brainstem, and cortex from Glra1 ${ }^{+/+}$(marked $\left.+/+\right)$, Glra $1^{+/ s h}(+/ s h)$, and Glra ${ }^{\text {sh/sh }}($ sh/sh) mice. B, GlyR protein expression profile in spinal cord, brainstem, and cortex at P21 in wild-type $(+/+)$, heterozygous $(+/$ sh), and homozygous animals (sh/sh). Gephyrin (geph) was detected at the appropriate molecular weight of $93 \mathrm{kDa}$; all GlyR $\alpha$ subunits were stained with a pan- $\alpha$ antibody (mAb4a, $48 \mathrm{kDa}$ ), GlyR $\alpha 1$ specifically with mAb2b (48 kDa); and $\beta$-actin was used as loading control (LC; $42 \mathrm{kDa}$ ). $\boldsymbol{C}, \boldsymbol{D}$, Quantification of GlyR $\alpha 1$ protein $\left(\boldsymbol{C}\right.$ and gephyrin $(\boldsymbol{D})$ in spinal cord and brainstem normalized to $\beta$-actin in wild-type $\left(G \mid r a 1^{+/+}\right)$and shaky $\left(G / r a ~^{\text {sh/sh }} ; n=6-10,{ }^{*} p<0.05\right.$, n.s.). $\boldsymbol{E}$, Strychnine- glycine competition in spinal cord tissue isolated from wild-type (pooled, $n=3$ ) and homozygous shaky mice (pooled, $n=4$ ), three independent experiments were performed. Thirty millimolar glycine bound to membrane preparations of tissue were displaced by $\left[{ }^{3} \mathrm{H}\right]$ strychnine using increasing concentrations of the radioactive antagonist $(0-200 \mathrm{nM})$. Note the increase in $\mathrm{K}_{D}$ in membrane preparations from shaky mice.

to increased GlyR $\alpha 1$ levels after birth was completed before the onset of symptoms at P14. Backcross into the oscillator line revealed a slight but nonsignificant decrease in GlyR $\alpha 1$ protein in heterozygous Glra1 ${ }^{+/ o t}$ and Glra1 $1^{\text {sh/ot }}$ animals, while the detection of all GlyR $\alpha$ variants in spinal cord tissue exhibited no differences among wild-type animals $\left(\mathrm{Glra1}^{+/+}\right)$, heterozygous shaky $\left(\mathrm{Glra1}^{+/ \mathrm{sh}}\right)$, oscillator $\left(\mathrm{Glra1}^{+/ \mathrm{ot}}\right)$, and Glra1 ${ }^{\text {sh/ot }}$ animals (Fig. $3 B, C$ ). Due to the Glral frameshift mutation in the oscillator line, Glra1 $1^{\text {ot } / o t}$ showed significantly reduced GlyR $\alpha 1$ levels $(2.5 \pm$ $1.3 \%$ ) and $40 \pm 17 \%$ GlyR expression levels corresponding to $\alpha 2$, $\alpha 3$, and $\beta$ subunits (Fig. 3C,D; Kling et al., 1997).

As a functional readout, we examined radioligand binding using spinal cord tissue from Glral ${ }^{\text {sh/sh }}$ mice compared with Glra1 ${ }^{+/+}$controls. When a saturating concentration of glycine
(30 mM) was replaced by increasing concentrations of $\left[{ }^{3} \mathrm{H}\right]$ strychnine (Fig. 2E), a higher strychnine concentration was required to displace glycine from spinal cord membranes of shaky mice (Glral ${ }^{\text {sh/sh }}, 40 \pm 4 \mathrm{nM}$; Glra1 $\left.{ }^{+/+}, 14 \pm 3 \mathrm{nM}\right)$. Although GlyR $\alpha 1$ expression in shaky mice is increased, binding of the antagonist strychnine is diminished. To analyze synaptic localization, we performed immunostaining of spinal cord tissue and samples from spinal cord cultures from Glra1 ${ }^{+/+}$and Glra1 $1^{\text {sh/sh }}$ mice. In contrast to wild-type GlyR $\alpha 1$, a fraction of GlyR $\alpha 1^{\text {Q177K }}$ was not colocalized with presynaptic markers synapsin and VGAT (Fig. $4 A, B$ ) or with the postsynaptic marker gephyrin (Fig. 4C). Quantification of synaptic GlyR $\alpha 1$ in neuronal cultures demonstrated a significant decrease in Glral ${ }^{\text {sh/sh }}$ compared with $\mathrm{Glra1}^{+/+}$ (gephyrin comparison between $\mathrm{Glra1}^{+/+}$and Glra1 ${ }^{\text {sh/sh }}, p=0.25$, 

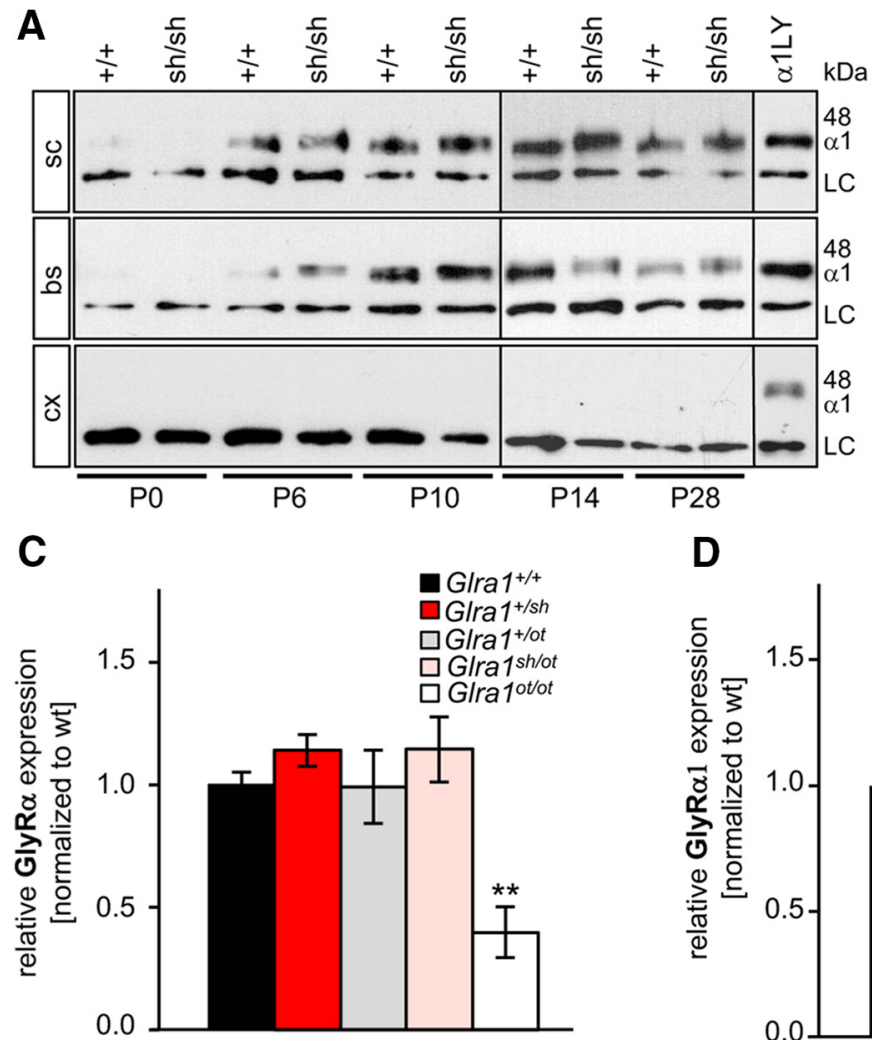

B

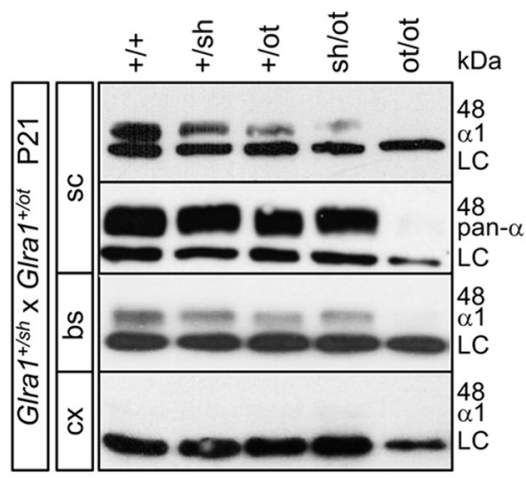

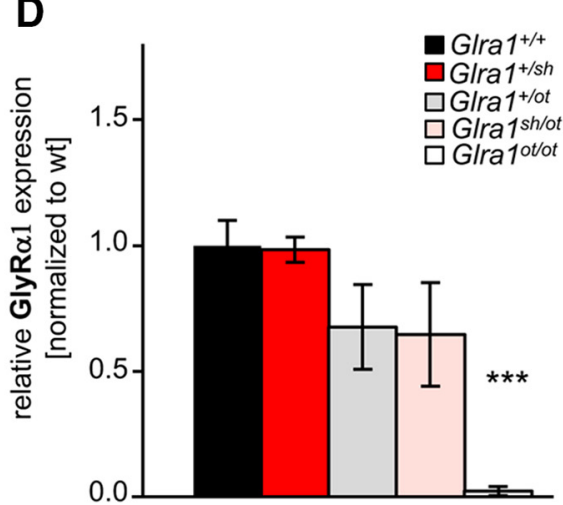

Figure 3. Developmental expression of the GlyR $\alpha 1$ subunit in shaky mice and after backcross into the mouse line oscillator. $A$, Spinal cord (sc), brainstem (bs), and cortex (cc; negative control) were analyzed at developmental stages P0, P7, P14, and P28 until severe symptoms in homozygous shaky mice compared with wild-type mice were observed. The GlyR $\alpha 1$ subunit was stained with the monoclonal mAb2b antibody at $48 \mathrm{kDa}$, with $\beta$-actin was used as a loading control (LC; $42 \mathrm{kDa}$ ). $\alpha 1 \mathrm{LY}$ represents a lysate control following transfection of GlyR $\alpha 1$ into $H E K 293$ cells and was used as a positive control. B, GlyR expression in P21 mouse tissue after backcross of shaky into the oscillator line. Sc, bs, and cx of mice carrying genotypes Glra ${ }^{+/+}$, heterozygous Glra $1^{+/ s h}$, Glra $^{+/ / 0 t}$,

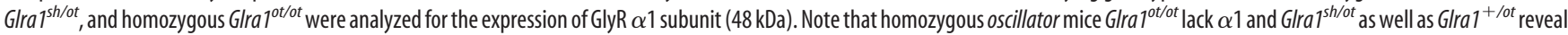
reduced GlyR $\alpha 1$ levels. Again, $\beta$-actin served as an LC ( $42 \mathrm{kDa}$ ). C, D, Quantification of GlyR $\alpha$ (pan- $\alpha$ antibody; ) and GlyR $\alpha 1$ protein (D) from spinal cord preparations of Glra ${ }^{+/+}{ }^{\text {, }}$, eterozygous

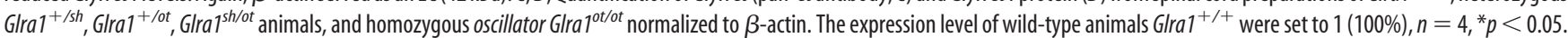
n.s. $=$ nonsignificant.

n.s.; GlyR $\alpha 1$ comparison between Glra1 ${ }^{+/+}$and Glra1 ${ }^{\text {sh/sh }},{ }^{*} p=$ 0.018 ; gephyrin compared with GlyR $\alpha 1$ in $G l r a 1^{+/+}, p=0.5$; gephyrin compared with GlyR $\alpha 1$ in Glral ${ }^{s h / s h},{ }^{\star} p=0.017, t$ test). An apparent increase in $\alpha 1^{\text {Q177K }}$ expression observed in shaky neurons may result from an attempt to compensate for the lack of synaptic $\alpha 1$-containing GlyRs (Fig. $4 D, E$ ). Hence, GlyR $\alpha 1$ Q177K expression is enhanced in brainstem and spinal cord, but synaptic localization is decreased. At the functional level, GlyRs in shaky mice display a lower strychnine-binding affinity, suggesting an additive effect of sorting deficits and functional disruption.

The $\alpha 1^{\text {Q177K }}$ mutation impairs the functionality of GlyR channels in vitro

Using overexpression of GlyRs in transfected HEK293 cells, quantification of whole-cell and plasma membrane protein of $\alpha 1{ }^{\mathrm{Q} 177 \mathrm{~K}} \beta$ GlyRs was compared with wild-type $\alpha 1 \beta$ receptors. This revealed a significant decrease of $\alpha 1^{\mathrm{Q} 177 \mathrm{~K}} \beta$ surface expression (heteromeric $\alpha 1{ }^{\mathrm{Q} 177 \mathrm{~K}} \beta 33 \pm 5 \%$ of wild-type $\alpha 1 \beta$, ${ }^{* *} p=$ $0.003, t$ test; Fig. $5 A$ ). In whole-cell recordings from transfected cells, it became obvious that $\alpha 1^{\mathrm{Q} 177 \mathrm{~K}} \beta$ cell surface GlyRs could form functional ion channels with no changes in maximal current amplitudes upon $1 \mathrm{~mm}$ glycine application (Fig. 5B) but with significantly lower current values at $100 \mu \mathrm{M}$ glycine $(\alpha 1 \beta, 4.7 \pm$ $0.3 \mathrm{nA} ; \alpha 1^{\mathrm{Q} 177 \mathrm{~K}} \beta, 1.13 \pm 0.3 \mathrm{nA} ;{ }^{* *} p=6.616 \mathrm{E}-06, t$ test; Fig. $5 B)$. In contrast, on application of $1 \mathrm{~mm} \beta$-alanine or taurine, $\alpha 1^{\mathrm{Q} 177 \mathrm{~K}} \beta$ GlyRs exhibited significantly reduced current ampli- tudes ( $\beta$-alanine, $3.2 \pm 0.3 \mathrm{nA}, n=11$; compared with $\alpha 1 \beta$, $4.5 \pm 0.6 \mathrm{nA}, n=9 ;{ }^{\star} p=0.033, t$ test; taurine, $2.8 \pm 0.4 \mathrm{nA}, n=$ 6 ; compared with $\alpha 1 \beta, 5.1 \pm 0.7 \mathrm{nA}, n=5,{ }^{\star} p=0.014, t$ test $)$. A concentration of $100 \mu \mathrm{M}$ for both partial agonists generated again significantly decreased agonist-induced currents compared with wild-type receptors $\left(\beta\right.$-alanine $\alpha 1^{\mathrm{Q} 177 \mathrm{~K}} \beta, 0.23 \pm 0.02 \mathrm{nA}, n=6$; compared with $\alpha 1 \beta, 1.1 \pm 0.2 \mathrm{nA}, n=6,{ }^{* *} p=0.0014, t$ test; taurine, $\alpha 1^{\mathrm{Q} 177 \mathrm{~K}} \beta 0.1 \pm 0.02 \mathrm{nA}, n=6$; compared with $\alpha 1 \beta$, $0.9 \pm 0.09 \mathrm{nA}, n=5,{ }^{* *} p=6.72 \mathrm{E}-06, t$ test; Fig. $\left.5 B\right)$.

Hence, the $\mathrm{EC}_{50}$ value for mutated $\alpha 1^{\mathrm{Q} 177 \mathrm{~K}} \beta$ channels activated by glycine increased by a factor of $6\left(\alpha 1 \beta \mathrm{EC}_{50}=40 \pm 6\right.$ $\mu \mathrm{M} ; \alpha 1^{\mathrm{Q}^{177 \mathrm{~K}}} \beta \mathrm{EC}_{50}=241 \pm 29 \mu \mathrm{M}$; Fig. $\left.5 C\right)$. The potencies of the partial agonists $\beta$-alanine $\left(\alpha 1^{\mathrm{Q} 177 \mathrm{~K}} \beta \mathrm{EC}_{50}=318 \pm 22 \mu \mathrm{M}\right.$; $\left.\alpha 1 \beta \mathrm{EC}_{50}=260 \pm 50 \mu \mathrm{M}\right)$ and taurine $\left(\alpha 1^{\mathrm{Q}^{177 \mathrm{~K}}} \beta \mathrm{EC}_{50}=389 \pm\right.$ $51 \mu \mathrm{M} ; \alpha 1 \beta \mathrm{EC}_{50}=212 \pm 34 \mu \mathrm{M}$ ) were almost unaffected with a slight decrease of 1.2- and 1.8-fold, respectively (Fig. 5C).

Desensitization decay time constants were significantly decreased for mutant receptors, arguing for faster ion channel closure of $\alpha 1^{\text {Q177K }} \beta$ heteromers compared with wild-type channels $\left(\alpha 1 \beta \tau=1.9 \pm 0.14 \mathrm{~s} ; \alpha 1{ }^{\mathrm{Q} 177 \mathrm{~K}} \beta \tau=0.88 \pm 0.19 \mathrm{~s} ;{ }^{\star} p=0.049\right.$, $t$ test; Fig. 5D). Last, artificial synapses were used to analyze the $\alpha 1^{\mathrm{Q} 177 \mathrm{~K}}$ mutation in the context of spontaneous glycine release from neighboring spinal cord interneurons. Spontaneous IPSPs (IPSCs) of $\alpha 1{ }^{\mathrm{Q} 177 \mathrm{~K}} \beta$ compared with $\alpha 1 \beta$ exhibited again a significant decrease in the decay time constant $\left({ }^{* *} p=5.2066 \mathrm{E}-5\right.$, $t$ test; Fig. 5E). 

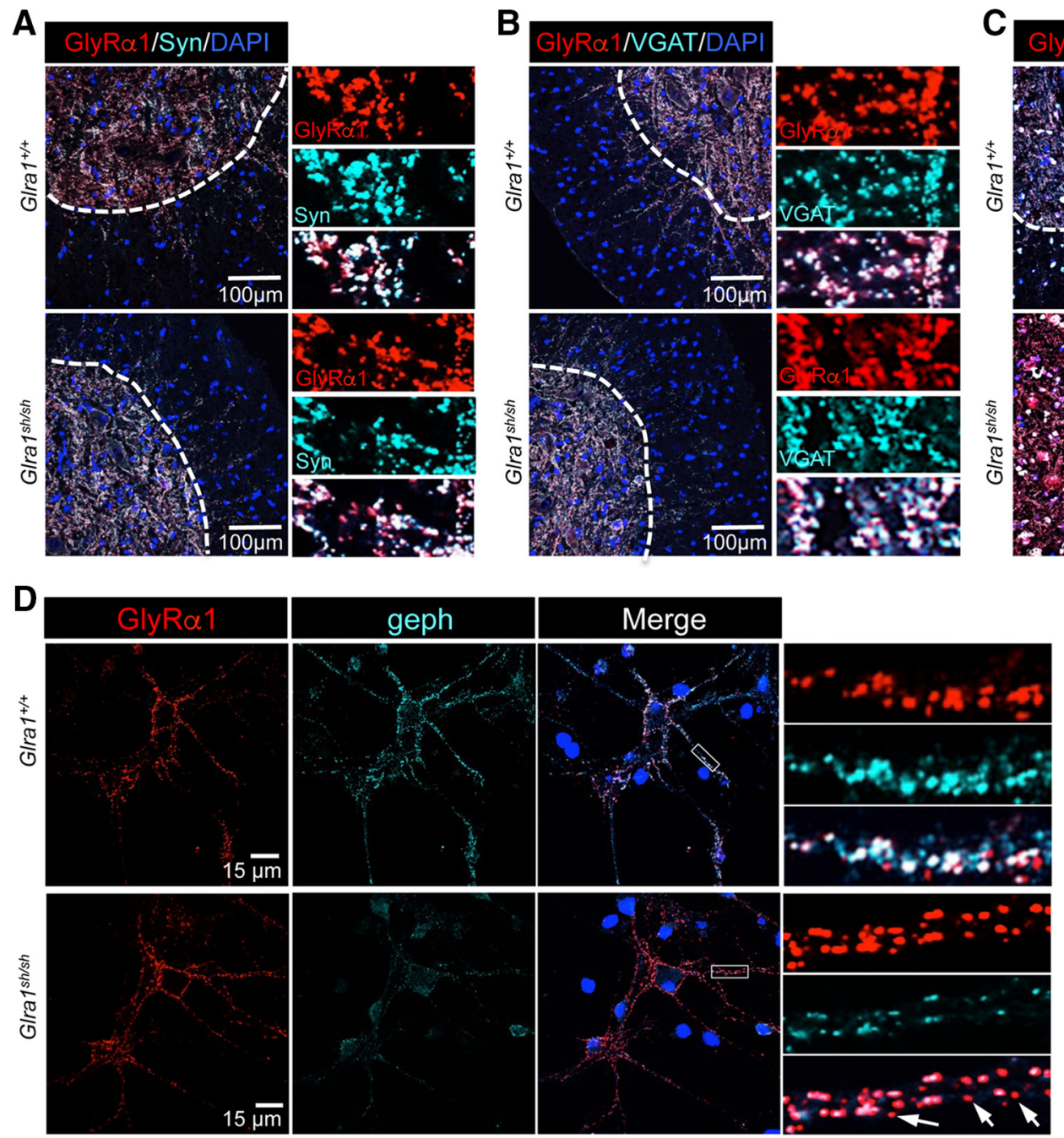

C GlyRa1/geph/DAPI
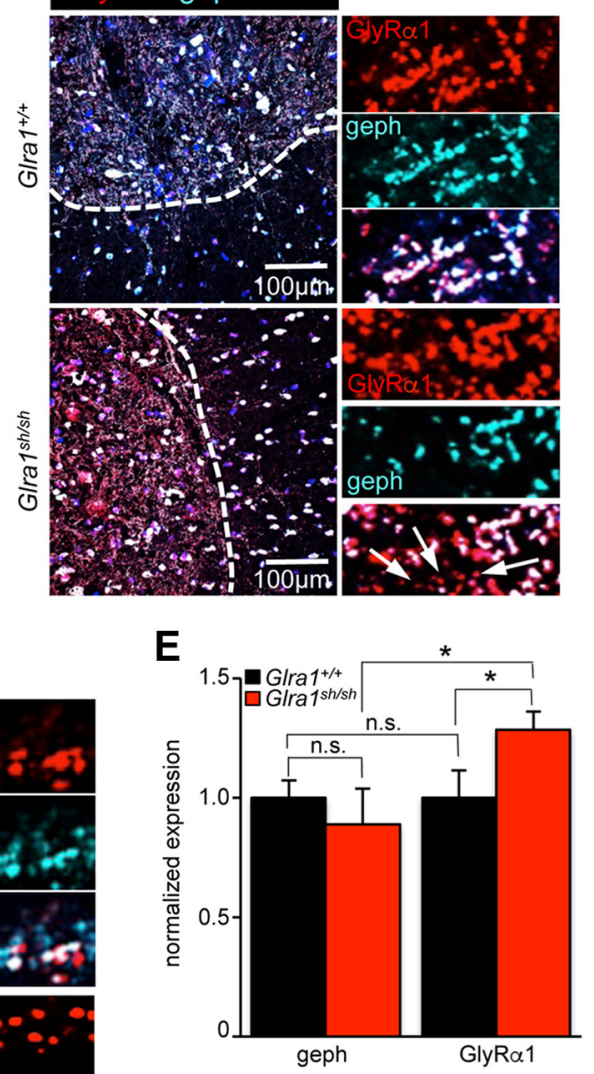

Figure 4. GlyR $\alpha 1^{\text {Q177K }}$ results in a lack of synaptic integration. A-C, Immunohistological stainings of spinal cord tissue from Glra ${ }^{+/+}$compared with homozygous Glra ${ }^{\text {sh/sh }}$ animals. Spinal cord slides $(9 \mu \mathrm{m})$ were stained for the GlyR $\alpha 1$ subunit with the monoclonal antibody mAb2b together with presynaptic markers synapsin (syn; $\boldsymbol{A}$ ) vesicular transporter (VGAT; $\boldsymbol{B}$ ) and the postsynaptic marker gephyrin (geph; $\boldsymbol{C}$. Ventral or dorsal horns are marked by a white dotted line. DAPI was used to stain nuclei. Right panels represent enlarged images of each staining. Note that there is less colocalization of GlyR $\alpha 1$ and gephyrin in homozygous shaky mice (white arrows). D, Spinal cord neuronal cultures from E13 embryos with genotypes Glra $1^{+/+}$or Glra ${ }^{\text {sh/sh }}$ were differentiated for 3 weeks in culture and stained for $\alpha 1$ (mAb2a) and gephyrin. An upregulation of GlyR $\alpha 1$ in shaky neurons was observed, but less colocalization in synaptic clusters with gephyrin (white arrows). Right panels represent enlarged dendrites of spinal cord neurons, which are marked by white boxes. $\boldsymbol{E}$, Quantification of synaptic clusters in neurons from Glra $1^{+/+}$and $G / r a 1^{\text {sh } / \text { sh }}$, $n=11$ from two independent experiments. The relative expression of gephyrin and GlyR $\alpha 1$ is shown $\left({ }^{*} p<0.05\right.$, n.s.), comparison of expression levels between $G /$ ra ${ }^{+/+}$and $G l$ ra $1^{\text {sh } / \text { sh }}$ and within each group.

The mutation Q177K disrupts GlyR function by faster ion channel closure

To investigate glycinergic synaptic signaling in intact synapses in situ, we prepared brainstem slices from wild-type and shaky mice and performed whole-cell recordings from neurons of the PreBötC, a nucleus rich in GlyR $\alpha 1$ expression and important for respiration. When strychnine-sensitive glycinergic IPSCs (Fig. 6A) were evoked at different stimulus intensities in PreBötC neurons at P18 to $\mathrm{P} 24$, a dramatically flattened input-output relationship in the mutant preparation was obtained $\left({ }^{* *} p<0.001\right.$ for all stimulus intensities; for values see the legend of Fig. $6 B$ ). Bath-applied glycine $(50 \mu \mathrm{M})$ caused a significant smaller baseline shift in Glral ${ }^{\text {sh/sh }}$ neurons compared with control, again suggesting a deficit in postsynaptic GlyR function $\left({ }^{* * *} p=0.0004, t\right.$ test; Fig. $6 C$ ). mIPSC recordings (in $1 \mu \mathrm{M}$ TTX) from PreBötC neurons to study individual glycinergic synapses revealed significantly lower frequency, smaller amplitudes, and accelerated decay in Glral $^{\text {sh/sh }}$ neurons (mIPSCs: Glral $^{+/+}$compared with
Glra1 ${ }^{\text {sh/sh }}$, amplitude ${ }^{\star} p=0.032$; frequency, ${ }^{\star} p=0.031$; decay, ${ }^{*} p=0.0017$; rise time, $p=0.423$, nonsignificant). These effects were independent from the block of spontaneous spiking by TTX (spIPSCs; Glra1 ${ }^{+/+}$compared with Glra1 ${ }^{\text {sh/sh }}$ : amplitude, ${ }^{* * *} p=$ 4.27E-06; frequency, ${ }^{* * *} p=2.55 \mathrm{E}-07$; decay, ${ }^{* * *} p=2.58 \mathrm{E}-06$; rise time, $p=0.211$, nonsignificant; Fig. $6 D, E)$.

Many PreBötC neurons receive mixed GABAergic/glycinergic inhibitory synaptic input with a corelease of both neurotransmitters from the same synaptic terminal (Rosenmund and Stevens, 1996). GABAergic spIPSCs, however, did not differ in frequency between the genotypes ( $p=0.067$, nonsignificant; Fig. 7 ), arguing against a generalized reduction in inhibitory synaptic terminal number or release probability as the main factor behind defects in glycinergic inhibition. To further exclude an overall decrease in motoneuron number as a modifier of the underlying pathology in shaky mice, the number of motoneurons was counted in lumbar spinal cord. No differences between $\mathrm{Glra1}^{+/+}$ and homozygous Glral ${ }^{\text {sh/sh }}$ animals were observed in six to seven 
A
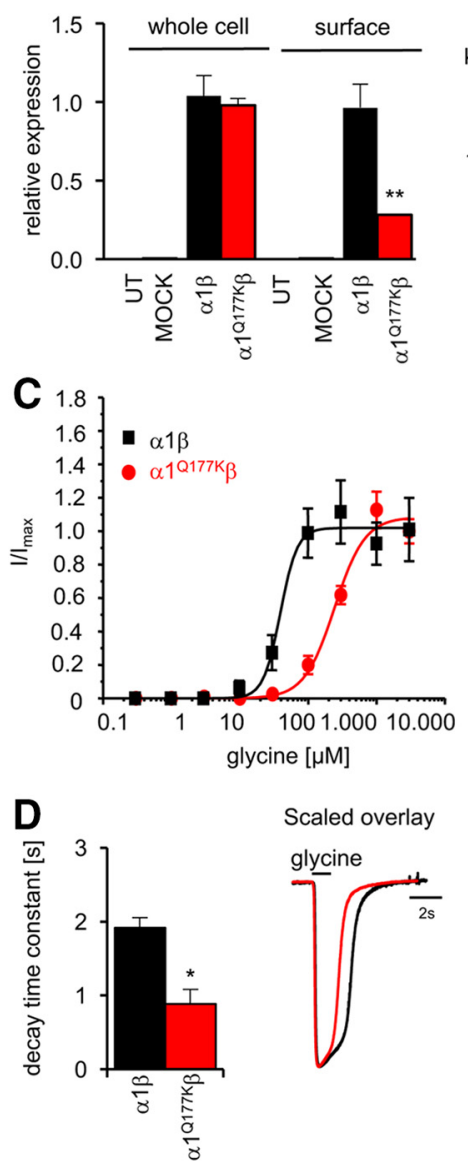
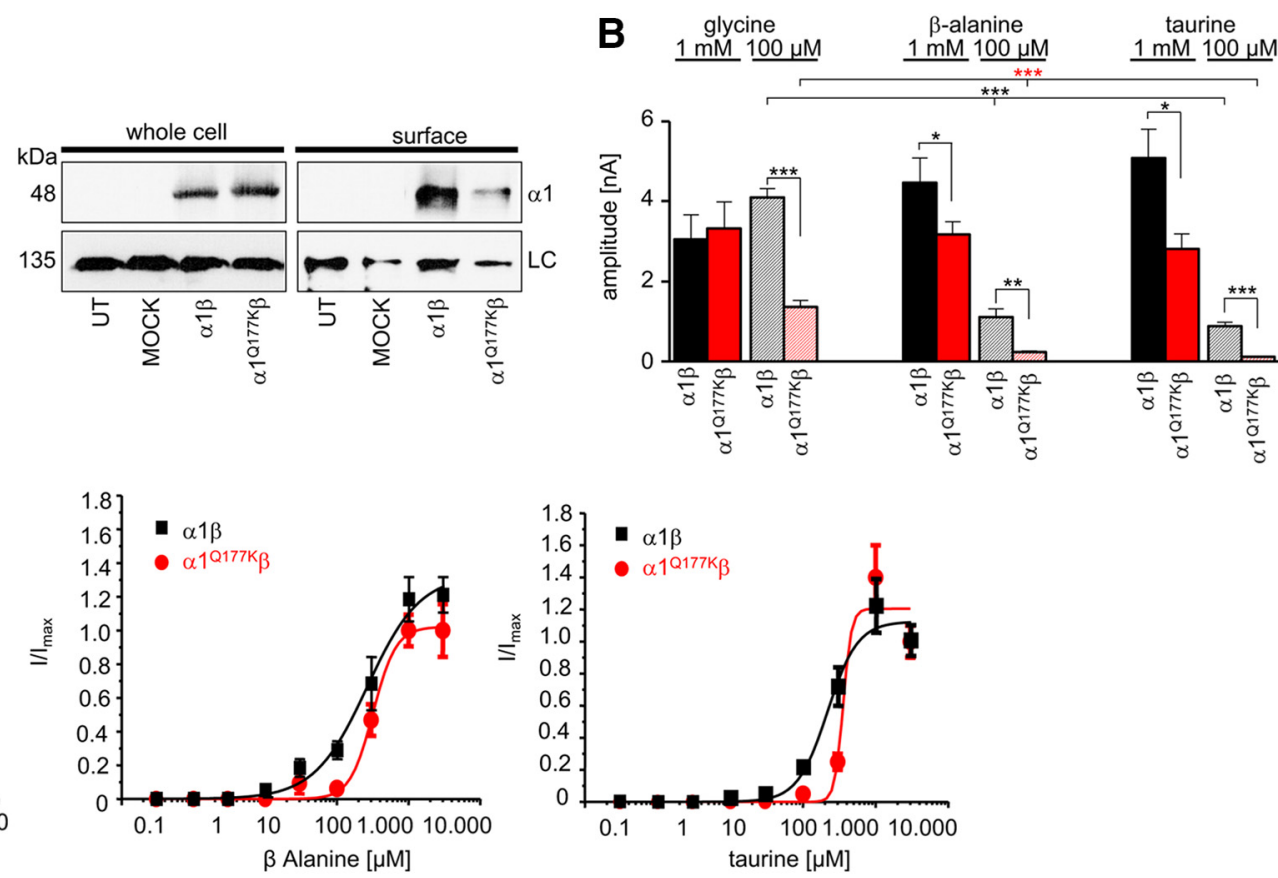

E
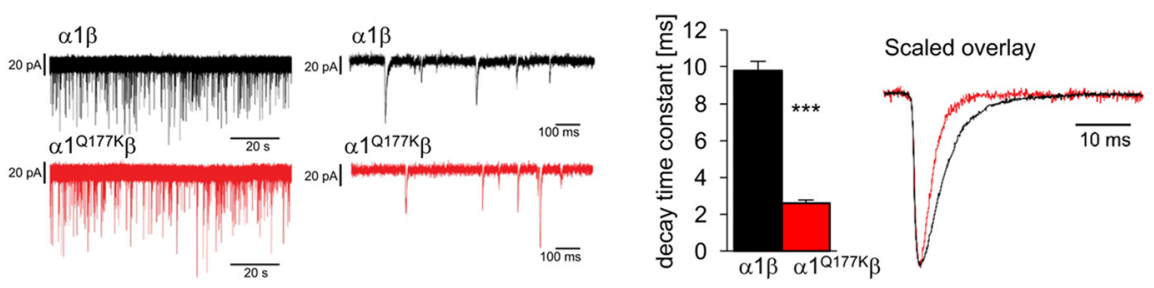

Figure 5. GlyR $\alpha 1^{Q 177 \mathrm{~K}}$ leads to reduced agonist potency and faster decay times. $A$, Expression of wild-type and mutant heteromeric receptor complexes following cotransfection with the GlyR $\beta$ subunit in HEK293 cells. Biotinylation assays were used to discriminate between surface and whole-cell protein. Left, Quantification of wild-type and mutant GlyR $\alpha 1$ protein with or without the GlyR $\beta$-subunit from whole-cell and surface pools normalized to pan-cadherin; data were obtained from at least three independent sets of experiments ( $n=3-6)$. Right, Western blot analysis of biotinylation assays. The monoclonal pan- $\alpha$ antibody was used for recognition of the GlyR $\alpha 1$ subunit (48 kDa), the membrane protein pan-cadherin served as a loading control (LC; $135 \mathrm{kDa})$. UT, Untransfected cells; MOCK, GFP-transfected cells. $\boldsymbol{B}$, Functional parameters from whole-cell recordings of transfected HEK 293 cells for $\alpha 1 \beta$ and $\alpha 1{ }^{0177 K} \beta$ heteromeric receptor configurations, with current amplitudes at $1 \mathrm{~mm}\left(\alpha 1 \beta, n=9 ; \alpha 1^{0177 \mathrm{~K}} \beta, n=16\right)$ and $100 \mu \mathrm{m}$ glycine $\left(\alpha 1 \beta, n=5 ; \alpha 1^{0177 \mathrm{~K}} \beta, n=5\right) ; 1 \mathrm{~mm}\left(\alpha 1 \beta, n=11 ; \alpha 1^{\mathrm{Q177K}} \beta, n=9\right)$ and $100 \mu \mathrm{m} \beta$-alanine $(\alpha 1 \beta, n=6$; $\left.\alpha 1^{0177 \mathrm{~K}} \beta, n=6\right)$; and $1 \mathrm{~mm}\left(\alpha 1 \beta, n=6 ; \alpha 1^{\text {Q177K }} \beta, n=5\right)$ and $100 \mu \mathrm{m}$ taurine $\left(\alpha 1 \beta, n=5 ; \alpha 1^{\text {Q177K }} \beta, n=6\right)$. C, Ligand-binding potencies (EC $\left.{ }_{50}\right)$ determined by current measurements of transfected cells expressing the heteromeric receptor configurations $\alpha 1 \beta$ and $\alpha 1^{\mathrm{Q177K}} \beta$ according to the adult in vivo receptor configuration at seven different glycine, $\beta$-alanine, and taurine concentrations ( $0.3-3.000 \mu \mathrm{m}, n=5$ for each receptor configuration and for the agonist used). The 1 mm concentration of the agonist glycine or the partial agonists $\beta$-alanine and taurine were used to determine $I_{\max }$ values. D, Decay times for desensitization. The decay currents were calculated in the presence of agonist (1 s). Right, Representative scaled current traces with $\alpha 1 \beta$ ( $n=5$, black) and $\alpha 1^{\text {Q177K }} \beta\left(n=6\right.$, red). E, Faster decay of shaky channels expressed in artificial synapses. Spontaneous IPSCs of $\alpha 1 \beta$ (black) and $\alpha 1^{\text {Q177K }} \beta$ (red) shown at two different time scales, 20 s and 100 ms. Quantification of decay time constants of $\alpha 1 \beta(n=10)$ and $\alpha 1^{0177 \mathrm{~K}} \beta(n=9)$ in artificial synapses/ enlarged scaled view of $\alpha 1 \beta$ (black) and $\alpha 1^{0177 \mathrm{~K}} \beta$ (red). $p<0.05 ;{ }^{* *} p<0.01$; *** $p<0.001$.

animals analyzed for each genotype ( $p=0.44$, nonsignificant, $t$ test; Fig. $8 A, B$ ). To conclude, the dramatically decreased amplitudes in glycine-evoked currents, mIPSCs, and spIPSCs explain the severity of the observed shaky phenotype. Similar to recordings from overexpressed cells as well as artificial synapses, decay times were accelerated in brainstem slice recordings, suggesting a function of the GlyR $\beta 8-\beta 9$ loop in the glycinergic signal transduction pathway.

\section{Q177K disrupts hydrogen bonding with residues in the ligand-binding pocket}

The recently uncovered cryo-EM structure of zebrafish GlyR $\alpha 1$ (PDB ID, 3JAE) provided evidence that the $\beta 8-\beta 9$ loop harboring the Q177K mutation is involved in ion channel opening/ closing processes (Du et al., 2015). Glycine was modeled into the GlyR structure based on the position of glutamate in the binding pocket of GluCl (Hibbs and Gouaux, 2011) by superposition of GluCl (PDB ID, 3RHW) onto the GlyR structure. The Q177K substitution was inserted into the glycine-bound open-channel state as part of $\beta$-strand 9 (Fig. $9 A-C$ ). The glycine-binding pocket comprises residues R65 and S129 from one subunit $(B)$ and F159, Y202, T204, and F207 from the adjacent subunit $(A$; Fig. 9C). R65 is crucial for ligand binding as it interacts with the $\alpha$-carboxyl and $\alpha$-amino groups of glycine (Grudzinska et al., 2005). The guanidinium group of R65 has an electrostatic interaction with the glycine carboxylate group (in the pocket), but also forms an additional H-bond with the Q177 side chain (Fig. 9D). The Q177K substitution is predicted to not only abolish the formation of the H-bond between Q177 and R65 but is also likely to alter the position of R65 side-chain due to the additional positive charge contributed by the lysine side-chain. This in turn could lead to destabilization of the glycine-binding pocket (Fig. 9E). In 
A $G / r a 1^{+/+}$
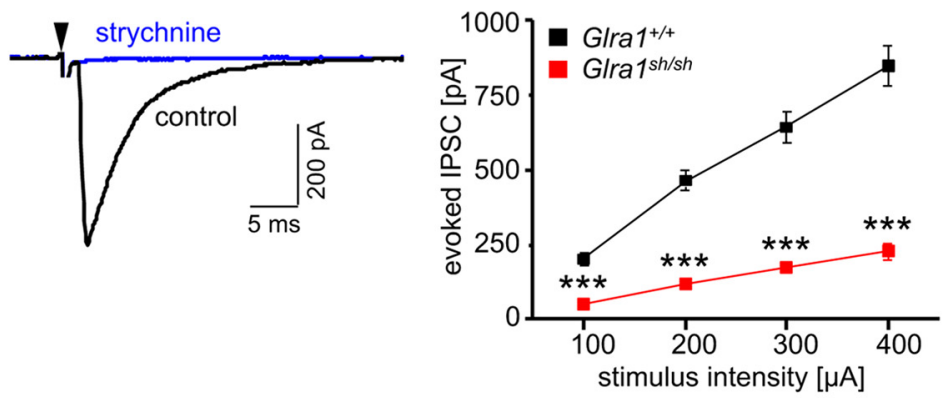

D

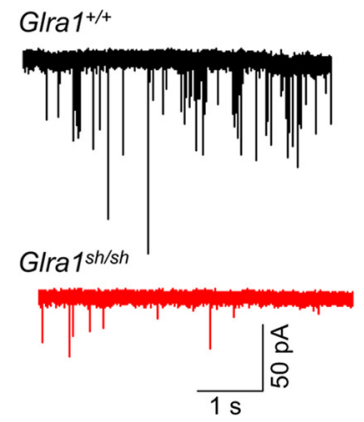

B

PreBötC neurons

averaged mIPSCs

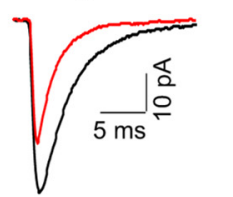

normalized

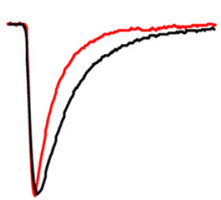

C

Glra $1^{1++}$

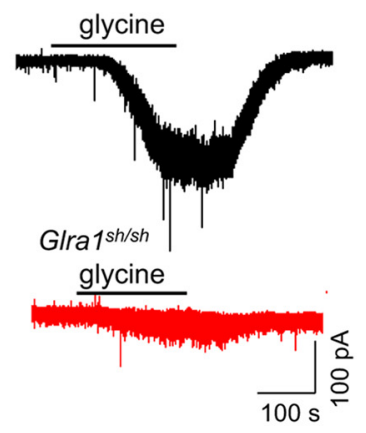

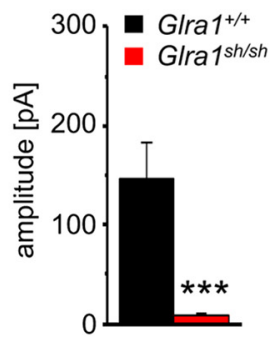

E PreBötC P18-24
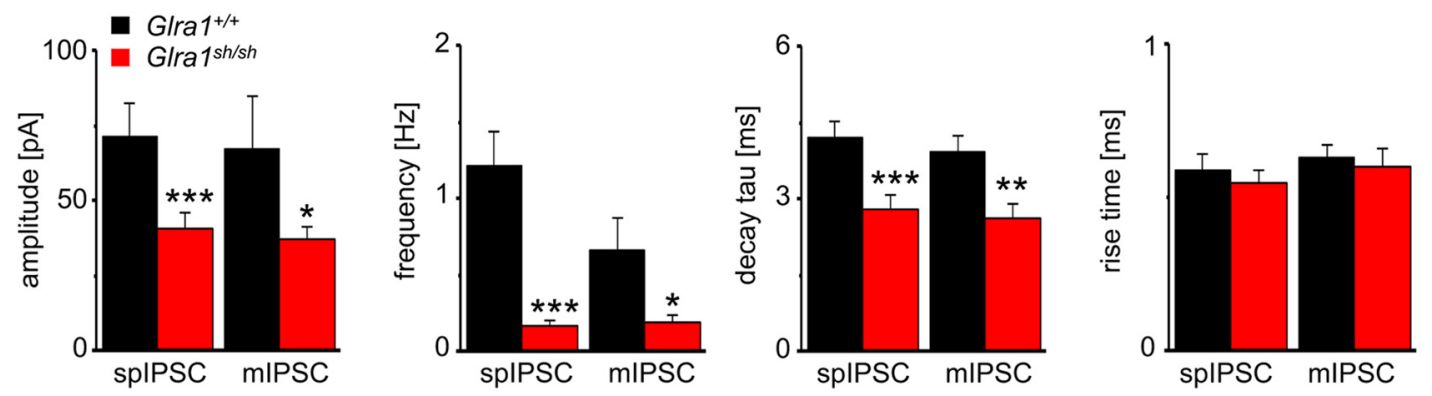

Figure 6. Shaky mice have impaired glycinergic synaptic transmission in PreBötC neurons. All recordings were made in whole-cell voltage-clamp mode in the presence of the ionotropic glutamate receptor antagonist KA (2 mM) and the GABA receptor antagonist bicuculline $(10 \mu \mathrm{m})$. $A$, Traces from a wild-type PreBötC neuron illustrate the evoked IPSC (at stimulation intensity of $200 \mu \mathrm{A}$ for $0.1 \mathrm{~ms})$ and sensitivity to strychnine $(10 \mu \mathrm{M})$. $\boldsymbol{B}$, Input- output curves of evoked IPSCS in Glra $1^{+/+}(n=24$ from 12 mice $)$ and Glra ${ }^{\text {sh } / \text { sh }}(n=25$ from 12 mice $)$ mice; comparison of Glra ${ }^{+/+}$and Glra ${ }^{\text {sh/sh }}$ at $100 \mu \mathrm{A}:{ }^{* * *} p=3.198 \mathrm{E}-09 ;$ at $200 \mu \mathrm{A},{ }^{* * *} p=1.539 \mathrm{E}-12 ;$ at $300 \mu \mathrm{A},{ }^{* * *} p=3.20 \mathrm{E}-12 ;$ at $400 \mu \mathrm{A},{ }^{* * *} p=3.32 \mathrm{E}-12, t$ test). C, Traces from wild-type and Glra ${ }^{\text {sh/sh }}$ neurons show postsynaptic current responses to glycine application $(50 \mu \mathrm{M})$, recorded in $\operatorname{TTX}(1 \mu \mathrm{M})$. Note the increase in baseline noise with glycine in Glra ${ }^{\text {sh/sh }}$ neuron, despite no shift in the holding current. Diagram on the right summarizes glycine-induced currents (Glra ${ }^{+/+}, n=7$ from 3 mice; Glra ${ }^{\text {sh/sh }}, n=9$ from 4 mice). D. Traces of spontaneously occurring mIPSCs, recorded in TTX ( $1 \mu \mathrm{m}$ ) from both genotypes, illustrate the reduced action potential-independent synaptic activity in $\mathrm{Glra}{ }^{5 h / s h}$ mice. Averaged mIPSCs from the two neurons were superimposed and normalized, revealing the strong decrease in amplitude and acceleration in decay for Glra ${ }^{\text {sh/sh }} \mathrm{mIPSCS}$. E, Quantitative analysis of spIPSCs (without TTX) and mIPSCs in PreBötC neurons demonstrates significant changes in properties and kinetics of spontaneously occurring events (splPSCs: Glra ${ }^{+/+}, n=17$ from 10 mice; Glra ${ }^{\text {th/sh }}, n=21$ from 12 mice; $\mathrm{mlPSCs}$ Glra ${ }^{+/+}, n=6$ from 3 mice; Glra ${ }^{\text {sh/sh }}, n=6$ from 4 mice). ${ }^{*} p<0.05 ;{ }^{* *} p<0.01 ;{ }^{* * *} p<0.001$.

summary, disrupted hydrogen bonding affecting key ligandbinding residues is likely to underlie the functional impairment shown by biochemical and physiological approaches and explains the severity of the shaky phenotype.

\section{Discussion}

Our results comprehensively illustrate the importance of the $\beta 8-\beta 9$ loop structure within the extracellular domain for GlyR ligand binding and the subsequent conformational changes enabling signal transduction and synaptic clustering. The current understanding of GlyR ion channel function suggests the coupling of movements within the ECD (loop C, $\beta 1-\beta 2, \beta 6-\beta 7$ ) upon ligand binding proceeding to elements of the ECD-transmembrane domain interface ( $\beta 10$-pre-M1, the M2-M3 loop). These conformational rearrangements result in tilting of transmembrane domains, enabling ion channel opening and closing
(Hassaine et al., 2014; Du et al., 2015; Gielen et al., 2015; Huang et al., 2015). The role of the $\beta 8-\beta 9$ loop, a flexible region localized at the complementary side of adjacent subunits underneath the ligand-binding pocket, has remained elusive due to the overall low electron density observed for this unstructured region of the ligand-binding site in earlier studies (Brejc et al., 2001; Hansen et al., 2005). Here, using the shaky mutant mouse that harbors a $\beta 8-\beta 9$ loop alteration, we found in vivo evidence that this extracellular loop is involved in stabilizing the GlyR ligand-binding site and ion channel gating. The pathogenic mechanism in this mouse mutant delineates a combined pattern of biogenesis defects resulting in defective synaptic integration, together with lower opening frequency, smaller amplitudes, and accelerated decay rates for remaining GlyRs, functional disturbances that are incompatible with survival. 


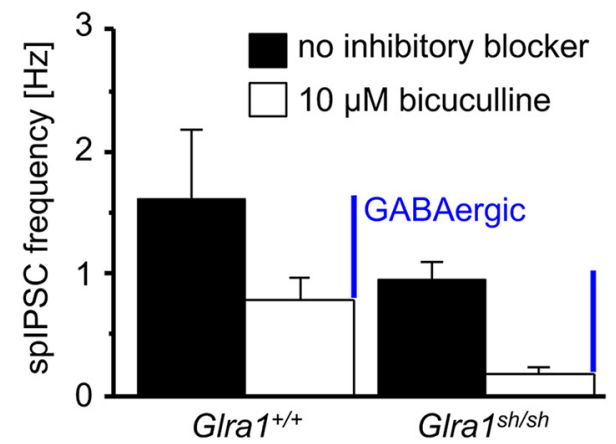

Figure 7. The shaky mutation does not affect GABAergic synaptic transmission in the PreBötC neurons. All recordings were made in the presence of KA ( $2 \mathrm{~mm})$. The frequency of GABAergic spIPSCs was calculated by comparing and subtracting the spIPSCs before and after bicuculline (10 $\mu \mathrm{m}$ ) application in the same neuron. PreBötC neurons from Glra $1^{\text {sh/sh }}$ mice have GABAergic spIPSCs at a frequency of $0.76 \pm 0.18 \mathrm{~Hz}$ ( $n=12$ from 9 mice), which is not different from that observed in Glra ${ }^{+/+}$neurons $(0.78 \pm 0.19 \mathrm{~Hz}, n=4$ from 4 mice).

In humans and rodents, mutations in GlyR subunit genes are associated with startle disease, characterized by exaggerated responses to acoustic stimuli and uncontrolled falling (Bode and Lynch, 2014) with an increased risk of cognitive deficits, such as learning difficulties or delay in speech acquisition (Thomas et al., 2013). The phenotype of the shaky mouse is in line with that of human patients, as well as strychnine poisoning (Buckwalter et al., 1994) and with other glycinergic mouse models (e.g., spastic, oscillator, and Nmf11; Traka et al., 2006; Schaefer et al., 2012). Our in vitro analysis revealed differences in surface expression between heteromeric wild-type $\alpha 1 \beta$ and mutant $\alpha 1^{\mathrm{Q} 177 \mathrm{~K}} \beta$ GlyRs. Mutant $\alpha 1^{\text {Q177K }} \beta$ GlyRs were able to form functional ion channels with increased $\mathrm{EC}_{50}$ values. However, the desensitization time constant decreased for $\alpha 1^{\mathrm{Q} 177 \mathrm{~K}} \beta$ GlyRs, indicating faster ion channel closure. The observed changes in vitro provided some explanations for the glycinergic defect present in vivo; however, the lethality of homozygous shaky mice presented a conundrum. A fivefold to sixfold reduction of GlyR agonist potency has also been documented in spasmodic mice carrying an A52S substitution in the $\beta 1-\beta 2$ loop of the GlyR $\alpha 1$ subunit ECD. In contrast to shaky mice, homozygous spasmodic mice display a normal life span and a mild neuromotor phenotype, arguing that the shift in agonist potency alone cannot explain lethality (Graham et al., 2011). Moreover, in vivo expression levels of $\alpha 1^{\mathrm{Q} 177 \mathrm{~K}}$ were increased in spinal cord and brainstem, although synaptic integration was significantly diminished. Synaptic integration of GlyRs is enabled by the scaffolding protein gephyrin via high-affinity binding to the intracellular M3-M4 domain of the GlyR $\beta$ subunit (Triller and Choquet, 2005; Dumoulin et al., 2010). A consequence of lower synaptic integration is less synaptic strength, which is normally regulated by lateral diffusion of synaptic and extrasynaptic receptors in and out of synapses (Triller and Choquet, 2005). The lower number of synaptic complexes argues that the extracellular binding site mutation is able to transduce conformational changes to the M3-M4 loop domain, thereby disrupting gephyrin binding and, thus, synaptic anchoring of $\alpha 1{ }^{\mathrm{Q} 177 \mathrm{~K}} \beta$ GlyRs. In turn, these data suggest that glycine sensitivity or gating properties of the receptor can be altered by the clustering status of the GlyR at the synapse. Another option that may explain the reduced synaptic integration is an enhanced turnover of the synaptic receptor pool via endocytosis as a neuronal adaptation to the impaired functionality of $\alpha 1^{\mathrm{Q} 177 \mathrm{~K}} \beta$ GlyRs in vivo. We therefore conclude that the
A
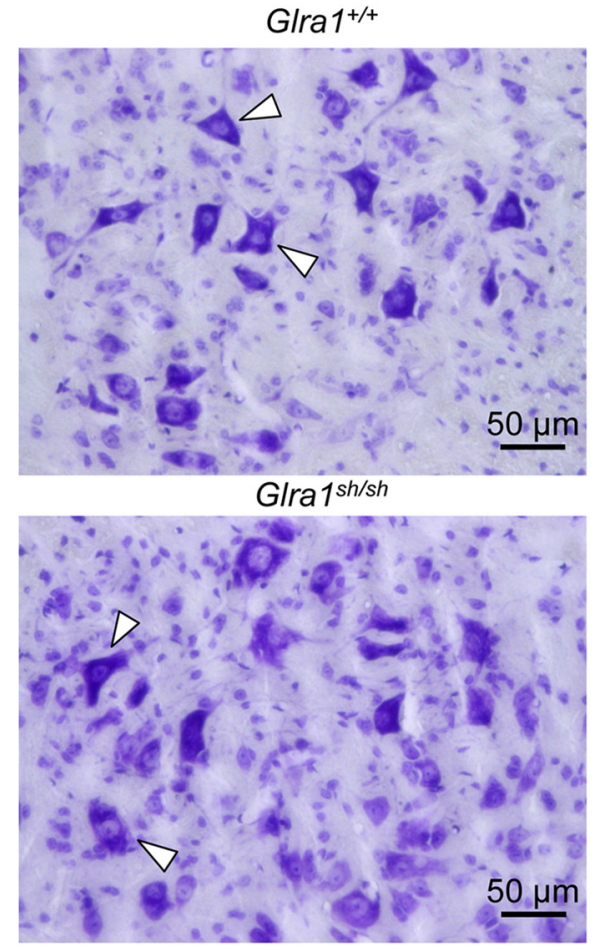

B

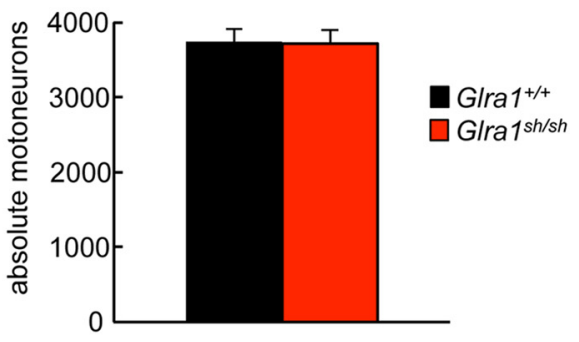

Figure 8. Glra1 $1^{+/+}$and $G / r a 1^{\text {sh/sh }}$ do not differ in motoneuron numbers. Lumbar spinal cord of Glra $1^{+/+}$and Glra ${ }^{\text {sh/sh }}$ at P28 was cut in $12.5 \mu \mathrm{m}$ slices, and the numbers of motoneurons were counted. Spinal cord slices were stained with cresyl violet, and motoneurons were determined due to their large cell body (white arrowheads). $\boldsymbol{A}$, Representative pictures from Glra ${ }^{+/+}$and Glra ${ }^{\text {sh/sh }}$ slices with large cell bodies of motoneurons. B, Quantitative analysis of motoneuron numbers. The quantification was made using six to seven animals of each genotype (Glra1 ${ }^{+/+}, n=6$; Glra1 $\left.{ }^{\text {sh/sh }}, n=7\right)$. Error bars represent SDs.

enhanced expression of $\alpha 1^{\mathrm{Q} 177 \mathrm{~K}}$ represents an unsuccessful attempt at neuronal compensation.

In addition to the postsynaptic effects of the shaky mutation, there may also be presynaptic consequences for functionally impaired homomeric $\alpha 1^{\mathrm{Q} 177 \mathrm{~K}}$ GlyRs. A potential role for presynaptic homomeric GlyRs in hyperekplexia has recently been demonstrated (Xiong et al., 2014). Presynaptic GlyR $\alpha 1$ subunit homomers have been described in calyceal synapses in the medial nucleus of the trapezoid body, in spinal cord and the ventral tegmental area (Turecek and Trussell, 2001; Jeong et al., 2003). Activation of these presynaptic GlyRs by glycine spillover triggers weakly depolarizing $\mathrm{Cl}^{-}$currents. The generated depolarization leads to enhanced transmitter release by $\mathrm{Ca}^{2+}$ channel activation and increased $\mathrm{Ca}^{2+}$ concentrations in the nerve terminal (Turecek and Trussell, 2001). The increase in $\alpha 1^{\mathrm{Q} 177 \mathrm{~K}}$ expression in vivo may result in an enhanced expression of presynaptic homomeric GlyRs generating impaired presynaptic GlyR activity and thus, diminished glycine release in the brainstem and spinal cord of shaky mice. Consequently, disrupted presynaptic GlyR func- 
A

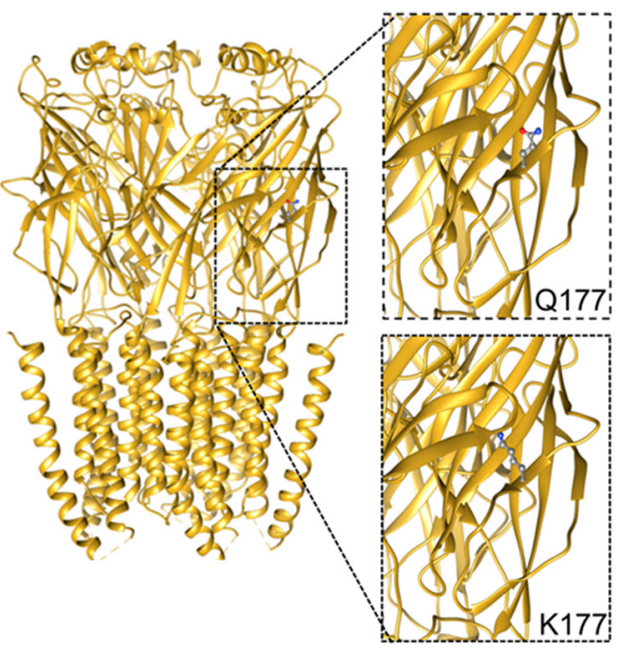

C

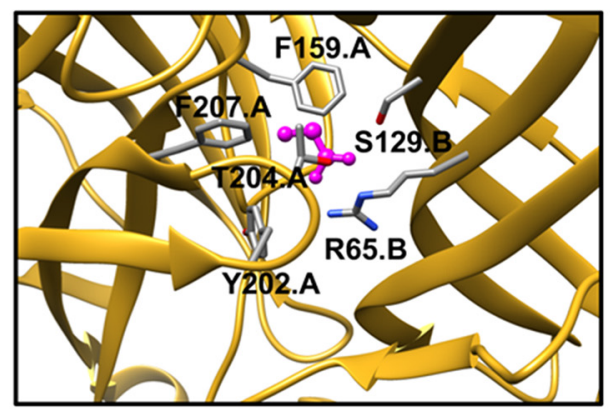

E

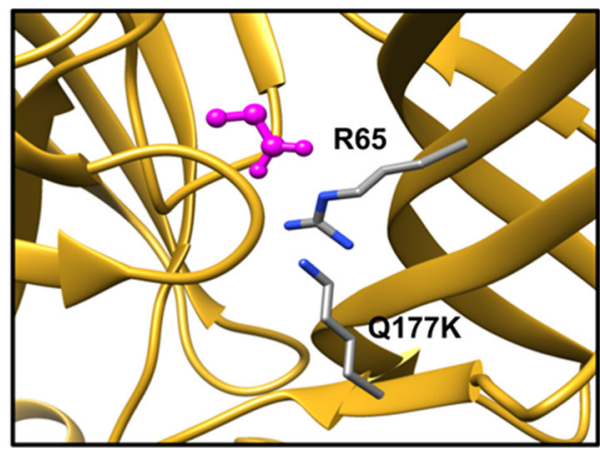

B

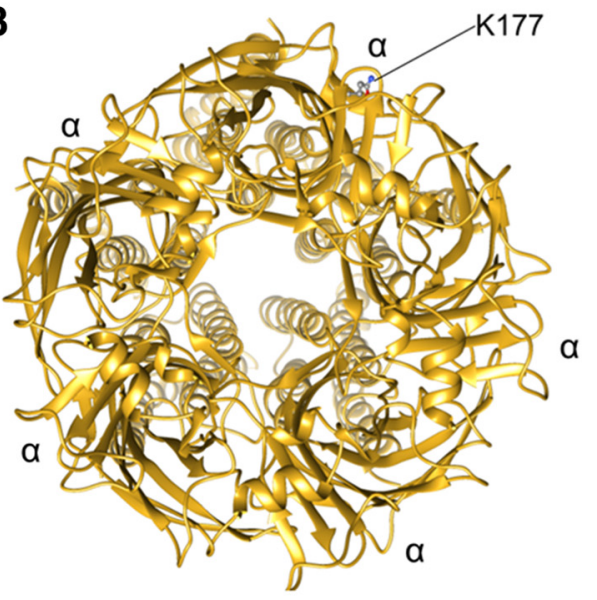

D

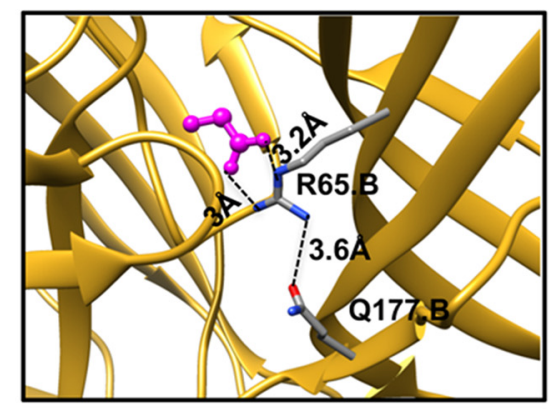

Figure 9. GlyR $\alpha 1^{\text {Q177K }}$ disrupts hydrogen bonding with the key ligand binding residue R65. $A$, Cryo-EM model 3JAE with the wild-type GlyR $\alpha 1$ ( $\alpha 1^{\text {Q177 }}$, top right) and the modeled shaky mutation ( $\alpha 1^{\mathrm{K} 177}$, bottom right). $\boldsymbol{B}$, Top view of the homo-pentameric arrangement and position of Q177K. $\boldsymbol{C}$, Glycine-binding pocket in the GlyR structure, where the glycine ligand is shown in magenta, and surrounding residues are labeled appropriately. D, Position of Q177 based on the cryo-EM model shown relative to the new position of R65 derived upon flexible fitting into the cryo-EM density using Flex-EM (Topf et al., 2008; Joseph et al., 2016). Interactions are indicated for Q177 with R65 from the glycine-binding pocket. $E$, The modeled Q177K substitution.

tion would be consistent with the significantly reduced IPSC frequencies we observed in brainstem slice recordings.

Functional analysis in brainstem nuclei that are rich in glycinergic synapses revealed largely reduced current amplitudes and significantly lower frequencies of spontaneous and miniature IPSCs in shaky mice, which are likely to be consequences of the low numbers of postsynaptic functional receptors and enhanced expression of functionally impaired presynaptic homomeric GlyRs. As the reduced ligand potency of shaky GlyRs is still within the range of glycine concentrations that can be achieved during synaptic activation, the observed functional deficits must result from disturbed translation of ligand binding into ion channel opening (gating). Impaired gating was further confirmed by reduced efficacies of the partial agonists $\beta$-alanine and taurine. Moreover, residue Q177 normally undergoes $\mathrm{H}$-bond formation with the ligand-binding residue R65, which is disrupted by the positively charged lysine. The positional change of the R65 side- chain due to the introduction of additional positive charge from K177 would in turn destabilize the glycine-binding pocket, which is in agreement with the observed decrease in glycine potency. The importance of the $\beta 8-\beta 9$ loop contribution to a hydrogen bond network in bound and unbound receptor states has been shown previously for $\gamma 2 \mathrm{GABA}_{\mathrm{A}}$ and $5 \mathrm{HT}_{3 \mathrm{~A}}$ as well as $\mathrm{nAChR}$ subunits (Nys et al., 2013).

The observed decrease in the decay time constant for the $\alpha 1^{\mathrm{Q} 177 \mathrm{~K}}$ mutation, resulting in faster ion channel closure is similar to spasmodic mice (Graham et al., 2006), arguing for a significant impact of ion channel decay mechanisms on the startle phenotype and in the case of shaky a contribution to the lethality in this mouse model. The functional analogy between spasmodic and shaky mice suggests a defect in the same signal transduction pathway determined by coupling of ECD movements following ligand binding to finally ion channel opening and closing (Du et al., 2015). Functional synaptic $\alpha 1^{\mathrm{Q} 177 \mathrm{~K}}$ GlyRs close much faster 
than wild-type channels, implying a fast unbinding process of the agonist. Since binding of glycine was only marginally affected in spinal cord tissue, the functional defects of $\alpha 1^{\mathrm{Q} 177 \mathrm{~K}}$ must result from downstream processes (e.g., fast transduction of ligandbound receptor into the closed conformation). These data are in line with the recently proposed model of signal transduction for GlyRs (Du et al., 2015; Morales-Perez et al., 2016; Nys et al., 2016). Thus, the integrity of the $\beta 8-\beta 9$ loop is a prerequisite for conformational rearrangements and is crucial during gating processes of the GlyR channel, which opens a novel window for therapeutics, resulting in prolonged open times. Accordingly, both the reduced synaptic integration and faster ion channel closure observed for GlyRs in shaky mice may also represent novel pathogenic mechanisms for human startle disease mutations. Together, our data reveal that the $\beta 8-\beta 9$ loop in the GlyR $\alpha 1$ ECD is a key regulator of glycinergic signaling. Furthermore, shaky represents the first in vivo mouse model demonstrating the incompatibility of a disrupted $\beta 8-\beta 9$ loop with life.

\section{References}

Atak S, Langlhofer G, Schaefer N, Kessler D, Meiselbach H, Delto C, Schindelin H, Villmann C (2015) Disturbances of ligand potency and enhanced degradation of the human glycine receptor at affected positions G160 and T162 originally identified in patients suffering from hyperekplexia. Front Mol Neurosci 8:79. CrossRef Medline

Bode A, Lynch JW (2014) The impact of human hyperekplexia mutations on glycine receptor structure and function. Mol Brain 7:2. CrossRef Medline

Bongianni F, Mutolo D, Cinelli E, Pantaleo T (2010) Respiratory responses induced by blockades of GABA and glycine receptors within the Botzinger complex and the pre-Botzinger complex of the rabbit. Brain Res 1344: 134-147. CrossRef Medline

Brejc K, van Dijk WJ, Klaassen RV, Schuurmans M, van Der Oost J, Smit AB, Sixma TK (2001) Crystal structure of an ACh-binding protein reveals the ligand-binding domain of nicotinic receptors. Nature 411:269-276. CrossRef Medline

Buckwalter MS, Cook SA, Davisson MT, White WF, Camper SA (1994) A frameshift mutation in the mouse alpha 1 glycine receptor gene (Glra1) results in progressive neurological symptoms and juvenile death. Hum Mol Genet 3:2025-2030. CrossRef Medline

Chung SK, Vanbellinghen JF, Mullins JG, Robinson A, Hantke J, Hammond CL, Gilbert DF, Freilinger M, Ryan M, Kruer MC, Masri A, Gurses C, Ferrie C, Harvey K, Shiang R, Christodoulou J, Andermann F, Andermann E, Thomas RH, Harvey RJ, et al (2010) Pathophysiological mechanisms of dominant and recessive GLRA1 mutations in hyperekplexia. J Neurosci 30:9612-9620. CrossRef Medline

Du J, Lü W, Wu S, Cheng Y, Gouaux E (2015) Glycine receptor mechanism elucidated by electron cryo-microscopy. Nature 526:224-229. CrossRef Medline

Dumoulin A, Triller A, Kneussel M (2010) Cellular transport and membrane dynamics of the glycine receptor. Front Mol Neurosci 2:28. CrossRef Medline

Dunbrack RL Jr (2002) Rotamer libraries in the 21st century. Curr Opin Struct Biol 12:431-440. CrossRef Medline

Gielen M, Thomas P, Smart TG (2015) The desensitization gate of inhibitory Cys-loop receptors. Nat Commun 6:6829. CrossRef Medline

Graham BA, Schofield PR, Sah P, Margrie TW, Callister RJ (2006) Distinct physiological mechanisms underlie altered glycinergic synaptic transmission in the murine mutants spastic, spasmodic, and oscillator. J Neurosci 26:4880-4890. CrossRef Medline

Graham BA, Tadros MA, Schofield PR, Callister RJ (2011) Probing glycine receptor stoichiometry in superficial dorsal horn neurones using the spasmodic mouse. J Physiol 589:2459-2474. CrossRef Medline

Grudzinska J, Schemm R, Haeger S, Nicke A, Schmalzing G, Betz H, Laube B (2005) The beta subunit determines the ligand binding properties of synaptic glycine receptors. Neuron 45:727-739. CrossRef Medline

Hansen SB, Sulzenbacher G, Huxford T, Marchot P, Taylor P, Bourne Y (2005) Structures of Aplysia AChBP complexes with nicotinic agonists and antagonists reveal distinctive binding interfaces and conformations. EMBO J 24:3635-3646. CrossRef Medline
Harvey RJ, Topf M, Harvey K, Rees MI (2008) The genetics of hyperekplexia: more than startle!. Trends Genet 24:439-447. CrossRef Medline

Hassaine G, Deluz C, Grasso L, Wyss R, Tol MB, Hovius R, Graff A, Stahlberg H, Tomizaki T, Desmyter A, Moreau C, Li XD, Poitevin F, Vogel H, Nury H (2014) X-ray structure of the mouse serotonin 5-HT3 receptor. Nature 512:276-281. CrossRef Medline

Hibbs RE, Gouaux E (2011) Principles of activation and permeation in an anion-selective Cys-loop receptor. Nature 474:54-60. CrossRef Medline

Hibbs RE, Sulzenbacher G, Shi J, Talley TT, Conrod S, Kem WR, Taylor P, Marchot P, Bourne Y (2009) Structural determinants for interaction of partial agonists with acetylcholine binding protein and neuronal alpha7 nicotinic acetylcholine receptor. EMBO J 28:3040-3051. CrossRef Medline

Huang X, Chen H, Michelsen K, Schneider S, Shaffer PL (2015) Crystal structure of human glycine receptor-alpha3 bound to antagonist strychnine. Nature 526:277-280. CrossRef Medline

Jablonka S, Schrank B, Kralewski M, Rossoll W, Sendtner M (2000) Reduced survival motor neuron (Smn) gene dose in mice leads to motor neuron degeneration: an animal model for spinal muscular atrophy type III. Hum Mol Genet 9:341-346. CrossRef Medline

James VM, Bode A, Chung SK, Gill JL, Nielsen M, Cowan FM, Vujic M, Thomas RH, Rees MI, Harvey K, Keramidas A, Topf M, Ginjaar I, Lynch JW, Harvey RJ (2013) Novel missense mutations in the glycine receptor beta subunit gene (GLRB) in startle disease. Neurobiol Dis 52:137-149. CrossRef Medline

Jeong HJ, Jang IS, Moorhouse AJ, Akaike N (2003) Activation of presynaptic glycine receptors facilitates glycine release from presynaptic terminals synapsing onto rat spinal sacral dorsal commissural nucleus neurons. J Physiol 550:373-383. CrossRef Medline

Joseph AP, Malhotra S, Burnley T, Wood C, Clare DK, Winn M, Topf M (2016) Refinement of atomic models in high resolution EM reconstructions using Flex-EM and local assessment. Methods 100:42-49. CrossRef Medline

Kling C, Koch M, Saul B, Becker CM (1997) The frameshift mutation oscillator (Glra1 (spd-ot)) produces a complete loss of glycine receptor alpha1polypeptide in mouse central nervous system. Neuroscience 78:411-417. CrossRef Medline

Masu Y, Wolf E, Holtmann B, Sendtner M, Brem G, Thoenen H (1993) Disruption of the CNTF gene results in motor neuron degeneration. Nature 365:27-32. CrossRef Medline

Morales-Perez CL, Noviello CM, Hibbs RE (2016) X-ray structure of the human alpha4beta2 nicotinic receptor. Nature 538:411-415. CrossRef Medline

Nys M, Kesters D, Ulens C (2013) Structural insights into Cys-loop receptor function and ligand recognition. Biochem Pharmacol 86:1042-1053. CrossRef Medline

Nys M, Wijckmans E, Farinha A, Yoluk Ö, Andersson M, Brams M, Spurny R, Peigneur S, Tytgat J, Lindahl E, Ulens C (2016) Allosteric binding site in a Cys-loop receptor ligand-binding domain unveiled in the crystal structure of ELIC in complex with chlorpromazine. Proc Natl Acad Sci U S A 113:E6696-E6703. CrossRef Medline

Pettersen EF, Goddard TD, Huang CC, Couch GS, Greenblatt DM, Meng EC, Ferrin TE (2004) UCSF Chimera-a visualization system for exploratory research and analysis. J Comput Chem 25:1605-1612. CrossRef Medline

Pilorge M, Fassier C, Le Corronc H, Potey A, Bai J, De Gois S, Delaby E, Assouline B, Guinchat V, Devillard F, Delorme R, Nygren G, Råstam M, Meier JC, Otani S, Cheval H, James VM, Topf M, Dear TN, Gillberg C, et al (2016) Genetic and functional analyses demonstrate a role for abnormal glycinergic signaling in autism. Mol Psychiatry 21:936-945. CrossRef Medline

Rosenmund C, Stevens CF (1996) Definition of the readily releasable pool of vesicles at hippocampal synapses. Neuron 16:1197-1207. CrossRef Medline

Sali A, Blundell TL (1993) Comparative protein modelling by satisfaction of spatial restraints. J Mol Biol 234:779-815. CrossRef Medline

Saul B, Schmieden V, Kling C, Mülhardt C, Gass P, Kuhse J, Becker CM (1994) Point mutation of glycine receptor alpha 1 subunit in the spasmodic mouse affects agonist responses. FEBS Lett 350:71-76. CrossRef Medline

Schaefer N, Vogel N, Villmann C (2012) Glycine receptor mutants of the 
mouse: what are possible routes of inhibitory compensation? Front Mol Neurosci 5:98. CrossRef Medline

Schaefer N, Langlhofer G, Kluck CJ, Villmann C (2013) Glycine receptor mouse mutants: model systems for human hyperekplexia. Br J Pharmacol 170:933-952. CrossRef Medline

Schaefer N, Kluck CJ, Price KL, Meiselbach H, Vornberger N, Schwarzinger S, Hartmann S, Langlhofer G, Schulz S, Schlegel N, Brockmann K, Lynch B, Becker CM, Lummis SC, Villmann C (2015) Disturbed neuronal ERGolgi sorting of unassembled glycine receptors suggests altered subcellular processing is a cause of human hyperekplexia. J Neurosci 35:422-437. CrossRef Medline

Sontheimer H, Becker CM, Pritchett DB, Schofield PR, Grenningloh G, Kettenmann H, Betz H, Seeburg PH (1989) Functional chloride channels by mammalian cell expression of rat glycine receptor subunit. Neuron 2:1491-1497. CrossRef Medline

Thomas RH, Chung SK, Wood SE, Cushion TD, Drew CJ, Hammond CL, Vanbellinghen JF, Mullins JG, Rees MI (2013) Genotype-phenotype correlations in hyperekplexia: apnoeas, learning difficulties and speech delay. Brain 136:3085-3095. CrossRef Medline

Thompson AJ, Padgett CL, Lummis SC (2006) Mutagenesis and molecular modeling reveal the importance of the 5-HT3 receptor F-loop. J Biol Chem 281:16576-16582. CrossRef Medline

Topf M, Lasker K, Webb B, Wolfson H, Chiu W, Sali A (2008) Protein structure fitting and refinement guided by cryo-EM density. Structure 16:295-307. CrossRef Medline

Traka M, Seburn KL, Popko B (2006) Nmf11 is a novel ENU-induced mutation in the mouse glycine receptor alpha 1 subunit. Mamm Genome 17:950-955. CrossRef Medline

Triller A, Choquet D (2005) Surface trafficking of receptors between synaptic and extrasynaptic membranes: and yet they do move!. Trends Neurosci 28:133-139. CrossRef Medline

Tsuriel S, Geva R, Zamorano P, Dresbach T, Boeckers T, Gundelfinger ED, Garner CC, Ziv NE (2006) Local sharing as a predominant determinant of synaptic matrix molecular dynamics. PLoS Biol 4:e271. CrossRef Medline

Turecek R, Trussell LO (2001) Presynaptic glycine receptors enhance transmitter release at a mammalian central synapse. Nature 411:587-590. CrossRef Medline

Tyagarajan SK, Fritschy JM (2014) Gephyrin: a master regulator of neuronal function? Nat Rev Neurosci 15:141-156. CrossRef Medline

Xiong W, Chen SR, He L, Cheng K, Zhao YL, Chen H, Li DP, Homanics GE, Peever J, Rice KC, Wu LG, Pan HL, Zhang L (2014) Presynaptic glycine receptors as a potential therapeutic target for hyperekplexia disease. Nat Neurosci 17:232-239. CrossRef Medline

Zhang Y, Dixon CL, Keramidas A, Lynch JW (2015) Functional reconstitution of glycinergic synapses incorporating defined glycine receptor subunit combinations. Neuropharmacology 89:391-397. CrossRef Medline 